\title{
WNT1-inducible signaling protein-1 mediates pulmonary fibrosis in mice and is upregulated in humans with idiopathic pulmonary fibrosis
}

Melanie Königshoff, ${ }^{1}$ Monika Kramer, ${ }^{1}$ Nisha Balsara, ${ }^{1}$ Jochen Wilhelm, ${ }^{1}$ Oana Veronica Amarie, ${ }^{1}$ Andreas Jahn, ${ }^{1}$ Frank Rose, ${ }^{2}$ Ludger Fink, ${ }^{1}$ Werner Seeger, ${ }^{1}$ Liliana Schaefer, ${ }^{3}$ Andreas Günther, ${ }^{1}$ and Oliver Eickelberg ${ }^{4}$

\begin{abstract}
1Department of Medicine, University of Giessen Lung Center, Giessen, Germany. ${ }^{2}$ Department of Radiotherapy, University of Marburg, Marburg, Germany. 3Department of Pharmacology and Toxicology, Goethe University of Frankfurt am Main, Frankfurt, Germany. ${ }^{4}$ Comprehensive Pneumology Center, Ludwig-Maximilians-University, Asklepios Hospital, and Helmholtz Zentrum München, Institute of Lung Biology and Disease (iLBD), Neuherberg/Munich, Germany.
\end{abstract}

\begin{abstract}
Idiopathic pulmonary fibrosis (IPF) is characterized by distorted lung architecture and loss of respiratory function. Enhanced (myo)fibroblast activation, ECM deposition, and alveolar epithelial type II (ATII) cell dysfunction contribute to IPF pathogenesis. However, the molecular pathways linking ATII cell dysfunction with the development of fibrosis are poorly understood. Here, we demonstrate, in a mouse model of pulmonary fibrosis, increased proliferation and altered expression of components of the WNT/ $\beta$-catenin signaling pathway in ATII cells. Further analysis revealed that expression of WNT1-inducible signaling protein-1 (WISP1), which is encoded by a WNT target gene, was increased in ATII cells in both a mouse model of pulmonary fibrosis and patients with IPF. Treatment of mouse primary ATII cells with recombinant WISP1 led to increased proliferation and epithelial-mesenchymal transition (EMT), while treatment of mouse and human lung fibroblasts with recombinant WISP1 enhanced deposition of ECM components. In the mouse model of pulmonary fibrosis, neutralizing mAbs specific for WISP1 reduced the expression of genes characteristic of fibrosis and reversed the expression of genes associated with EMT. More importantly, these changes in gene expression were associated with marked attenuation of lung fibrosis, including decreased collagen deposition and improved lung function and survival. Our study thus identifies WISP1 as a key regulator of ATII cell hyperplasia and plasticity as well as a potential therapeutic target for attenuation of pulmonary fibrosis.
\end{abstract}

\section{Introduction}

Pulmonary fibrosis can occur secondary to lung injury - provoked by, for example, chemotherapy, toxin inhalation, or collagen vascular disease - or as an idiopathic entity in the form of idiopathic interstitial pneumonias (IIPs) $(1,2)$. Idiopathic pulmonary fibrosis (IPF; also termed cryptogenic fibrosing alveolitis) is the most common form of IIP and exhibits a poor prognosis and unresponsiveness to currently available therapies $(2-5)$. Respiratory failure, due to distortion of the normal lung architecture, develops in patients with IPF as a result of alveolar epithelial cell damage that drives enhanced (myo)fibroblast proliferation and activation and, ultimately, increased deposition of ECM in the lung interstitium $(4,6)$. The hallmark lesions of IPF are fibroblast foci, which are aggregates of activated myofibroblasts promoting excessive ECM deposition. Fibroblast foci occur in subepithelial layers, close to areas of alveolar epithelial cell injury and repair $(7,8)$. The presence of fibroblast foci constitutes an important prognostic factor, as their numbers have been correlated with survival in $\operatorname{IPF}(9,10)$.

Conflict of interest: The authors have declared that no conflict of interest exists. Nonstandard abbreviations used: ATII, alveolar epithelial type II; Ccng1, cyclin G1; Col1a1, type I collagen $\alpha 1$; CTGF, connective tissue growth factor; ECAD, E-cadherin; EMT, epithelial-mesenchymal transition; GSK-3 $\beta$, glycogen synthase kinase- $3 \beta$; IIP, idiopathic interstitial pneumonia; IPF, idiopathic pulmonary fibrosis; OCCL, occludin; panCK, pan-cytokeratin; qRT-PCR, quantitative RT-PCR; SPC, pro-surfactant protein C; TJP, tight junction protein; WISP, WNT1-inducible signaling protein. Citation for this article: J. Clin. Invest. 119:772-787 (2009). doi:10.1172/JCI33950.
The pathogenetic mechanisms of IPF, however, remain enigmatic. IPF resembles a lung remodeling process originating from dysregulated wound repair in response to local inflammation (11) and, at the same time, a disorder of inappropriate alveolar regeneration in response to repetitive epithelial injuries (3). It is well accepted that alveolar epithelial cell injury and subsequent repair, in the presence or absence of local inflammation, represent a key pathogenic feature consistently observed in patients with IPF and animal models of lung fibrosis, such as the bleomycin-induced mouse model $(3,6,12,13)$. Impaired epithelial-mesenchymal crosstalk between alveolar epithelial type II (ATII) cells and subepithelial fibroblasts, as well as dysregulated precursor cell recruitment, have been shown to contribute to the pathobiology of $\operatorname{IPF}(12,14,15)$. It is currently unclear, however, whether increased apoptosis and/or proliferation of ATII cells, or a combination thereof, represents the initial trigger for enhanced ECM deposition in lung fibrosis.

In IPF, active ECM deposition occurs within fibroblast foci in close proximity to hyperplastic ATII cells, but little information about the specific phenotype, as well as gene regulatory networks, of ATII cells in lung fibrosis is currently available. In the present study, we comprehensively characterized gene expression patterns of ATII cells freshly isolated from fibrotic mouse lungs, using whole genome microarray analysis. We report increased proliferation and altered gene expression profiles of ATII cells in lung fibrosis. In particular, we demonstrate that the $\mathrm{WNT} / \beta$-catenin signaling pathway is activated in the epithelium during lung fibrosis. WNT1-inducible signaling protein 1 (WISP1) RNA and pro- 
A

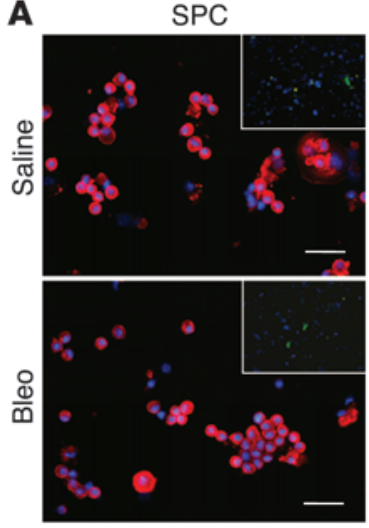

C

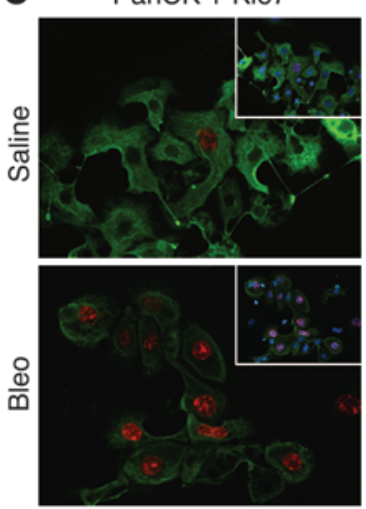

B

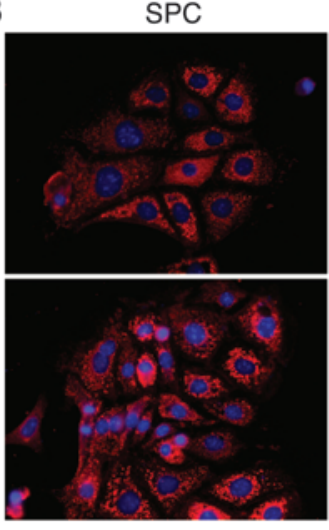

D

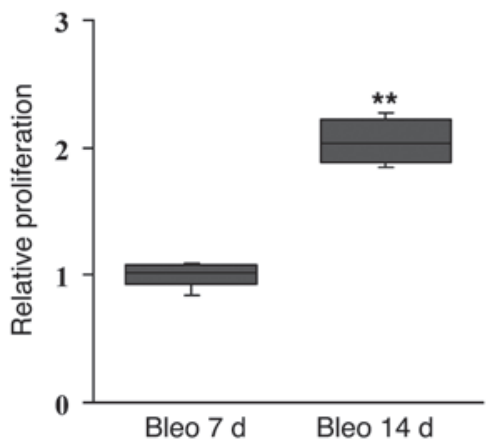

TJP1
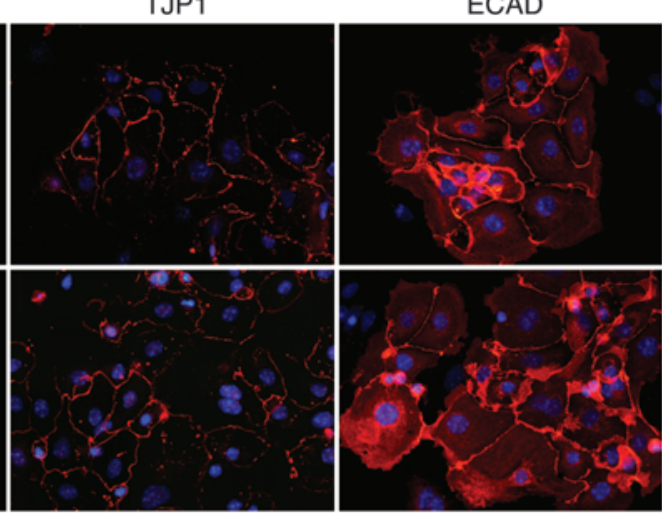

E

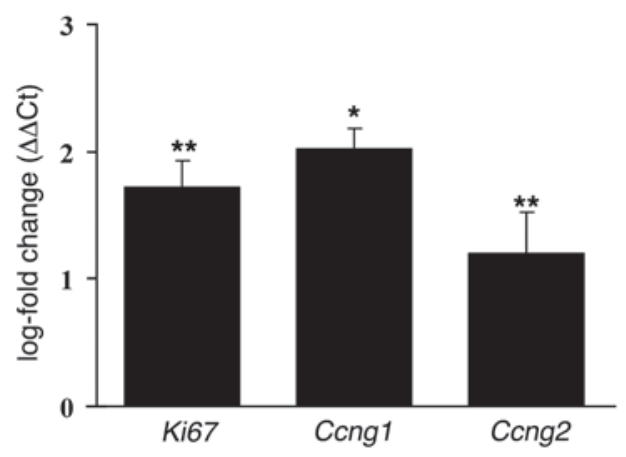

Figure 1

Enhanced proliferative capacity of ATII cells in experimental lung fibrosis. The purity (A) and phenotype (B) of ATII cell isolations from saline- or bleomycin-treated (Bleo) mice, 14 days after instillation, was analyzed by immunofluorescence staining. ATII cells were fixed directly after isolation (cytocentrifuge preparations) and stained with antibodies against the ATII cell marker SPC (original magnification, $\times 40$, scale bar: $10 \mu \mathrm{m}$ ) or the (myo)fibroblast marker $\alpha$-SMA (insets, magnification, $\times 10)(\mathbf{A})$ or fixed after 24 hours of attachment and subsequently stained with antibodies against SPC, TJP1, or ECAD (original magnification, $\times 40$ ) (B). (C) Double immunostaining for panCK (green) and Ki67 (red) was performed in primary ATII cells from saline- or bleomycin-treated mice, 14 days after instillation (original magnification, $\times 40$ ). Nuclei were visualized by DAPI staining (insets; original magnification, $\times 40$ ). All stainings are representative of at least 3 independent experiments. (D) ATII cell proliferation was analyzed in primary cells isolated from mice 7 or 14 days after instillation with bleomycin by $\left[{ }^{3} \mathrm{H}\right]$ thymidine incorporation. Data are presented as fold change in $\left[{ }^{3} \mathrm{H}\right]$ thymidine incorporation compared with saline-instilled controls ( $n=10$ per group). (E) mRNA levels of the proliferation markers Ki67, Ccng1, and Ccnb2 were analyzed by qRT-PCR using primary ATIl cells and plotted as log-fold increase ( $\Delta \Delta \mathrm{Ct})$ of mRNA levels in bleomycin- versus saline-treated mice, 14 days after instillation $\left(n=6\right.$ each). Results are presented as mean $\pm \mathrm{SEM}$; ${ }^{\star} P<0.05$, ${ }^{*} P<0.02$.

tein expression were highly upregulated in experimental and idiopathic lung fibrosis. Enhanced WISP1 protein expression localized to hyperplastic ATII cells in vitro and in vivo. WISP1 treatment of primary ATII cells resulted in increased ATII cell proliferation, profibrotic marker gene expression, and epithelial-mesenchymal transition (EMT). In contrast, WISP1 treatment of primary fibroblasts resulted in enhanced ECM deposition but did not affect their proliferation. Finally, depletion of WISP1 (using neutralizing antibodies) resulted in marked attenuation of bleomycin-induced lung fibrosis and improved survival in vivo. Thus, our study identified WISP1 as a cell type-specific regulator in lung fibrosis in vitro and in vivo and highlights WISP1 as a potential therapeutic target in pulmonary fibrosis.

\section{Results}

Enhanced expression of WISP1 in proliferating ATII cells in experimental lung fibrosis. We initially characterized primary ATII cells in lung fibrosis by investigating the morphology and proliferative capacity of freshly isolated ATII cells from mice subjected to bleomycininduced lung fibrosis, as well as from time-matched, saline-treated control mice. A similar purity was observed when isolating ATII cells from control or bleomycin-treated mouse lungs $(95 \% \pm 3 \%$ of pro-surfactant protein $\mathrm{C}$-positive [SPC-positive] and $\alpha$-SMA-negative cells) (Figure 1A). Morphological analysis revealed the expression of the epithelial marker proteins SPC, tight junction protein 1 (TJP1), and E-cadherin (ECAD) (Figure 1B; for secondary antibody controls, see Supplemental Figure 1; supplemental material available online with this article; doi:10.1172/JCI33950DS1) as well as occludin (OCCL) and pan-cytokeratin (panCK) (Supplemental Figure 1B) in both cell isolations. ATII cells isolated from the lungs of bleomycin-treated mice, however, demonstrated a significant increase in cell proliferation, as assessed by Ki67 staining and $\left[{ }^{3} \mathrm{H}\right]$ thymidine incorporation $(186 \%-225 \%$ of control ATII cells, 95\% CI) (Figure 1, C and D). In accordance with these observa- 
A $\quad 3.0 \quad 1: 1 \quad-3.0$

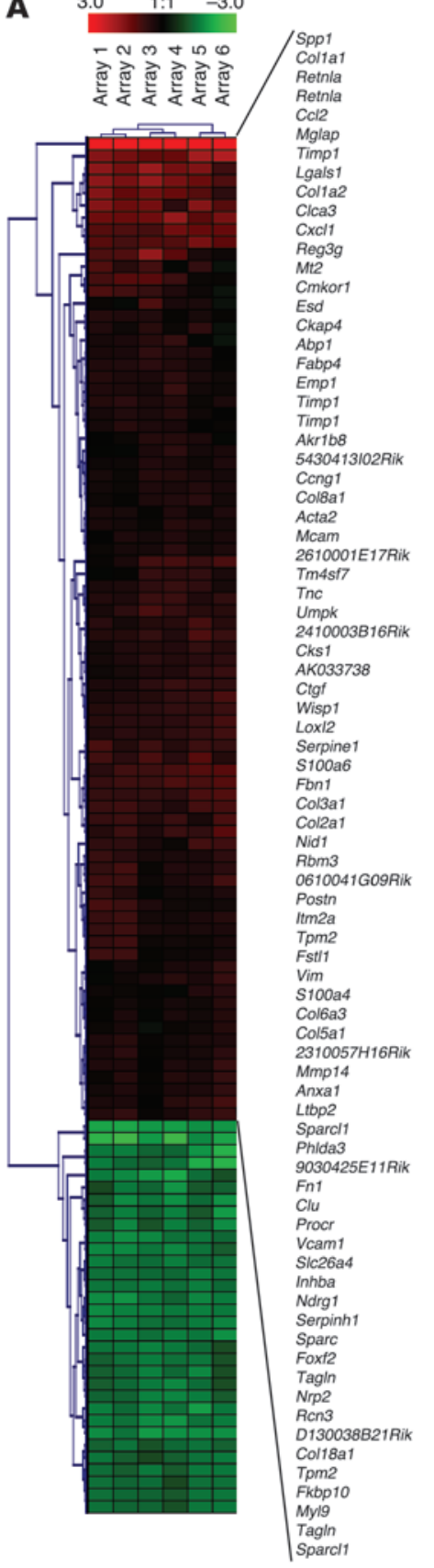

$\mathbf{B}$
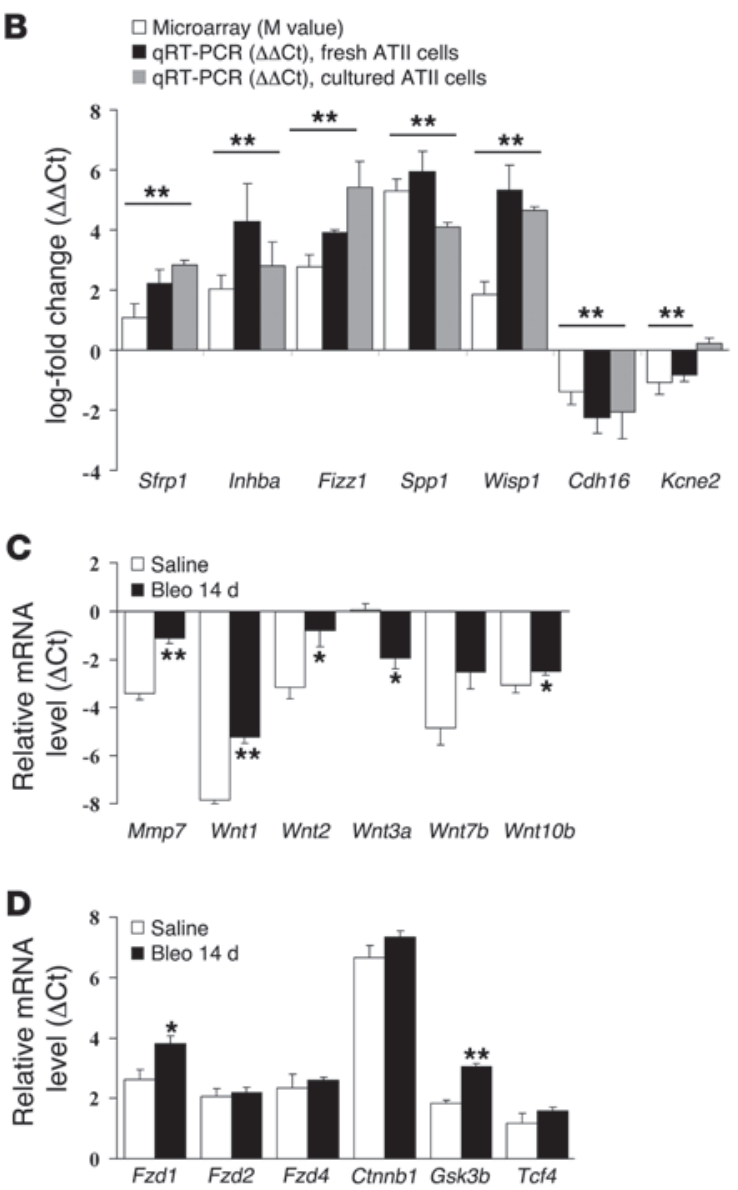

Figure 2

Increased mRNA expression of Wisp1 and WNT signaling components in ATII cells isolated from bleomycin-treated mice. (A) ATIl cell gene expression profiles were analyzed by whole genome expression analysis using RNA from freshly isolated ATII cells from saline- or bleomycin-treated mouse lungs 14 days after administration. Red and green indicate increased and decreased gene expression levels, respectively, in ATII cells isolated from bleomycin- versus saline-treated mice. Columns represent individual samples, including dye-swap experiments. Selected genes are represented in rows. Detailed description of the whole genome expression analysis is given in the Supplemental Data. (B) Confirmation of microarray results was performed for selected genes in freshly isolated ATII cells $(n=6)$, as well as in ATII cells 72 hours after isolation $(n=3)$ by qRT-PCR, as indicated. The following genes were analyzed: secreted frizzled-related protein 1 (Sfrp1), inhibin beta A (Inhba), found in inflammatory zone 1 (Fizz1), secreted phosphoprotein 1 (Spp1), Wisp1, cadherin 16 (Cdh16), and potassium voltage-gated channel subfamily $\mathrm{E}$ member 2 (Kcne2). Results are presented as mean \pm SEM; ${ }^{* *} P<0.02$ for all bars, compared with ATII cells isolated from saline-treated mice. (C and D) The mRNA levels of the WNT target gene Mmp7, the WNT ligands Wnt1, Wnt2, Wnt3a, Wnt7b, and Wnt10b (C), the receptors frizzled 1 (Fzd1), Fzd2, and Fzd4, and the intracellular signal transducers Ctnnb1, Gsk3b, and Tcf4 (D) were assessed in ATII cells isolated from bleomycin- and saline-treated mice ( $n=6$ each) by qRT-PCR. Results are presented as mean \pm SEM. ${ }^{*} P<0.05$, ${ }^{* \star} P<0.02$. tions, ATII cells from bleomycin-treated mice exhibited increased mRNA levels of the proliferation markers Ki67, cyclin G1 (Ccng1), and Ccnb2, when compared with time-matched, saline-treated mice (Figure 1E). To uncover potential gene regulatory networks driving increased ATII cell proliferation, we next performed whole genome microarray analysis comparing gene signatures of freshly isolated ATII cells from bleomycin-treated mice with those from saline-instilled mice. As depicted in Figure 2 and Supplemental Figure 2, several gene families were differentially expressed in ATII cells obtained from fibrotic lungs, the details of which are outlined in the Supplemental Data. In accordance with our initial observations, ATII cells isolated from fibrotic mouse lungs demonstrated a remarkable upregulation of proliferative mediators and/or markers, such as oncogenes and cell cycle-associated genes (Supplemental Figure 2). Furthermore, the ATII cell gene expression profile also indicated an enrichment of inflammatory stimuli and proinflammatory cytokines in experimental lung fibrosis, suggesting that, at least in the mouse, this is part of the alveolar epithelial cell response to fibrogenic stimuli.

Differentially expressed transcripts also included genes that have previously been reported to be upregulated in bleomycin-induced lung fibrosis and IPF, including Spp1 (16, 17), Timp1 (18), Sfrp1 (19), and Pai1 (20). To confirm these findings, we further investigated the gene expression profiles in an independent set of freshly isolated and short term-cultured (48 hours) ATII cells by quantitative RT-PCR (qRT-PCR) (Figure 2B), and the findings were essen- 


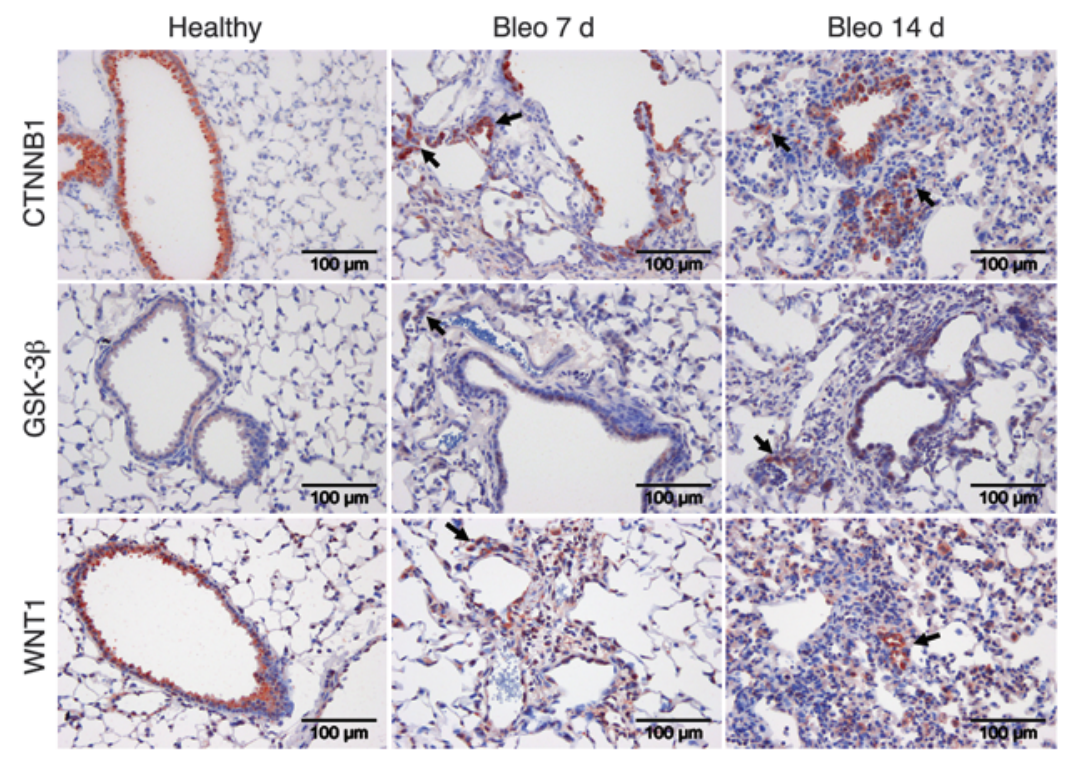

\section{Figure 3}

Increased epithelial expression of WNT/ $\beta$-catenin signaling components in experimental lung fibrosis. Immunohistochemical staining for CTNNB1, GSK-3 $\beta$, and WNT1 was performed on whole-lung sections of saline- or bleomycin-treated mice 7 or 14 days after bleomycin application, as indicated. The arrows indicate distinct alveolar epithelial cells. Stainings are representative of 2 independent experiments using at least 3 different bleomycin- or saline-treated lung tissues. tially the same as in the microarray analysis. Of interest, the expression of genes of the WNT signaling pathway (Wnt10a, Sfrp1, Tcf4, Cond1) was upregulated in ATII cells during bleomycin-induced lung fibrosis. In particular, expression of Wisp1, a member of the recently described CCN family of secreted signaling molecules (21, 22), was highly upregulated (Figure 2B).

Increased expression of WNT/ $\beta$-catenin signaling molecules in lung epithelial cells during experimental lung fibrosis. The WNT family of highly conserved secreted growth factors is essential to organ development and known to determine epithelial cell fate $(23,24)$. The canonical WNT signaling pathway, or $\beta$-catenin-dependent pathway, regulates gene transcription by stabilization of $\beta$-catenin. Upon WNT stimulation, receptor activation leads to glycogen synthase kinase-3 $\beta$ (GSK-3 $\beta$ ) phosphorylation, thereby preventing $\beta$-catenin phosphorylation by GSK-3 $\beta$. As a result, $\beta$-catenin accumulates, translocates to the nucleus, and regulates target gene expression via interaction with the $\mathrm{T}$ cell-specific transcription factors (TCFs) $(23,24)$.

As recently demonstrated, this pathway is expressed and operative in adult lung epithelium in $\operatorname{IPF}(25,26)$. To further elucidate whether WNT/ $\beta$-catenin activation is an early event in experimental lung fibrosis, as indicated by our initial gene expression analysis, we sought to quantify the mRNA expression of canonical WNT/ $\beta$-catenin signaling components in ATII cells isolated from the lungs of bleomycin- or saline-treated mice. The investigated WNT ligands were variably expressed in ATII cells, and Wnt1, Wnt2, Wnt7b, and Wnt10b mRNA levels were markedly upregulated, whereas $W n t 3 a$ was significantly downregulated (Figure 2C). The common WNT receptors frizzled 1-4 (Fzd1-4), as well as the intracellular signal transducers Gsk3b, Ctnnb1, and Tcf4, were expressed in ATII cells, with a relatively high abundance of Ctnnb1. Fzd1 and Gsk3b were significantly upregulated in ATII cells of bleomycin-treated mice (Figure 2D). To further confirm cell-specific expression of the WNT/ $\beta$-catenin signaling molecules, we identified the cell types capable of WNT secretion and signaling by immunohistochemistry of WNT1, CTNNB1, and GSK-3 $\beta$ (Figure 3). All signal components were largely expressed in bronchial and alveolar epithelium, with enhanced staining of alveolar epithe- lial cells in bleomycin-treated mouse lungs in early and advanced stages of lung fibrosis (Figure 3, arrows).

Active WNT/ $\beta$-catenin signaling in vivo during the development of experimental lung fibrosis. TOPGAL reporter mice were used next to localize the activation of the $\mathrm{WNT} / \beta$-catenin pathway in vivo in experimental lung fibrosis. The detailed treatment scheme is outlined in Supplemental Figure 3. Mice were treated orotracheally with either recombinant WNT3A, to demonstrate the capability of the lung to activate $\mathrm{WNT} / \beta$-catenin signaling (Figure $4 \mathrm{~A}$, top row), or bleomycin, to induce lung fibrosis (Figure 4A, bottom row). As depicted, bronchial and alveolar epithelial cells routinely stained for $\beta$-gal in response to WNT3A or bleomycin. Examination of mouse lungs harvested at different time points after a single administration of bleomycin revealed an activation of $\mathrm{WNT} / \beta$-catenin signaling as early as 5 days after the initial injury, with distinct bronchial and alveolar epithelial cells responding to WNT activation (Figure $4 \mathrm{~A}$ ). The epithelial nature of cells with active WNT signaling was further confirmed by colocalization of $\beta$-gal and the ATII cell marker SPC and the clara cell-specific protein (CCSP), respectively (Figure 4B). Increased expression of the WNT target genes Ccnd1 and Wisp1 upon WNT3A stimulation in primary ATII cells in vitro further confirmed these results (Figure 4C).

Increased expression of WISP1 in ATII cells in vitro and in vivo in experimental and idiopathic pulmonary fibrosis. Based on the evidence that (a) the WNT target WISP1 was one of the most highly regulated genes in ATII cells isolated from fibrotic mouse lungs and (b) active WNT signaling is present in lung fibrosis, we focused our further studies on WISP1 as a potential novel mediator and amenable therapeutic target. WISP1 is a member of the CCN family of matricellular proteins, which consist of CYR61/CCN1, connective tissue growth factor/CCN2 (CTGF/CCN2), NOV/CCN3, WISP1/ CCN4, WISP2/CCN5, and WISP3/CCN6 $(21,27,28)$. Except for CCN5, all CCN proteins comprise 4 conserved cysteine-rich modular domains. They act through binding to specific integrin receptors and heparin sulfate proteoglycans or modulating the activities of other growth factors and cytokines, thereby triggering a variety of cell functions, such as mitosis, adhesion, and migration of multiple cell types (27). CCN family members have been associated 
A

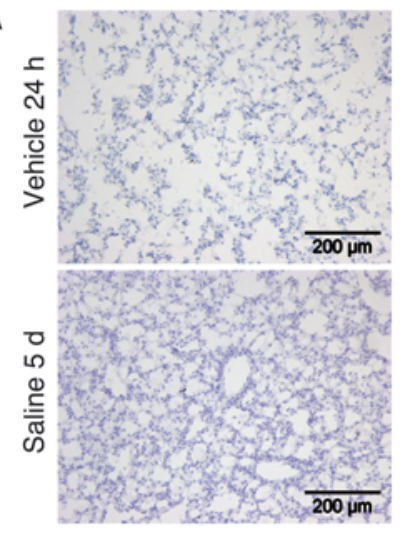

B

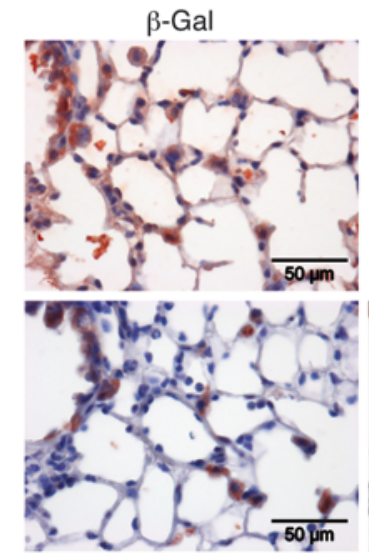

SPC
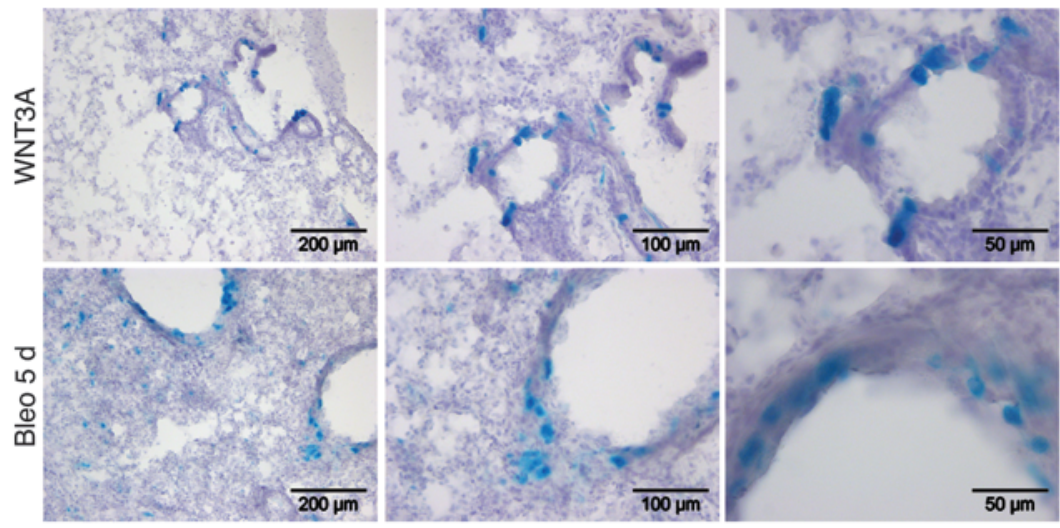

C

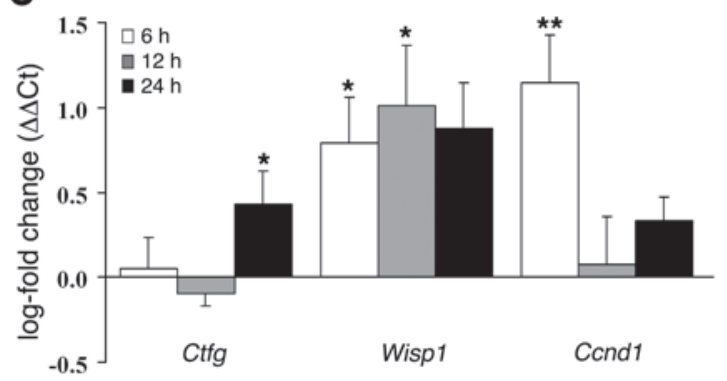

\section{Figure 4}

Activation of WNT/ $\beta$-catenin signaling in vivo during experimental lung fibrosis. TOPGAL reporter mice were treated orotracheally with WNT3A or bleomycin, as described in detail in Methods. Supplemental Figure 3 depicts the treatment scheme. (A) X-gal staining of $\beta$-gal activity in lungs from WNT3A- and vehicle-treated mice (top row) or bleomycin- and saline-treated mice (bottom row). Pictures are representative of at least 2 independent experiments using at least 4 different lung tissues for each condition. (B) X-gal, SPC, and clara cell-specific protein (CCSP) protein expression in serial whole-lung sections from bleomycin-treated TOPGAL reporter mouse was assessed by immunohistochemistry. (C) Primary ATII cells were stimulated with WNT3A $(100 \mathrm{ng} / \mathrm{ml})$, and the mRNA levels of Ctgf, Wisp 1 , and Ccnd1 were analyzed by qRT-PCR $(n=4$ for each) at the indicated time points and plotted as log-fold increase $(\Delta \Delta \mathrm{Ct})$ of mRNA levels in WNT-stimulated versus unstimulated cells. Results are presented as mean \pm SEM; ${ }^{*} P<0.05$, ${ }^{* *} P<0.02$.

with different developmental and disease processes; however, little is known about WISP1 and WISP2.

We next analyzed the expression of all CCN family members in vivo in mice subjected to bleomycin-induced lung fibrosis. Of the 6 CCN family members, Wisp1 mRNA exhibited the highest fold increase in lung homogenates during bleomycin-induced lung fibrosis (Figure 5A). WISP1 protein localized to ATII cells in vivo, as documented by immunohistochemistry, and increased expression in lung homogenates was demonstrated by Western blot analysis (Figure 5B). In support of this finding, Wisp1 mRNA exhibited the highest fold upregulation of all CCN family members in isolated ATII cells, but not primary fibroblasts, isolated from bleomycin-treated mouse lungs (Figure 5C), underscoring that WISP1 originates from ATII cells during lung fibrosis. WISP1 expression was increased at the protein level in isolated ATII cells, as documented by coimmunofluorescence staining of WISP 1 and ECAD (Figure 5D).

We next investigated whether increased WISP1 expression was also evident in human lung tissues derived from IPF patients. To this end, we analyzed the mRNA levels of all CCN family members in lung specimens obtained from IPF (usual interstitial pneumonia [UIP] pattern) or control (transplant donors) patients. With the exception of WISP3, all CCN family members were expressed in human lungs (Figure 6A). WISP1 demonstrated the lowest overall lung mRNA expression but the greatest difference in expression in IPF compared with donor lung homogenates. Furthermore, increased expression of WISP1 mRNA was detectable in septae obtained by laser-assisted microdissection from IPF compared with donor lungs (Figure 6B). qRT-PCR analysis of primary human ATII cells and fibroblasts further revealed that WISP1, and to a lesser extent $C T G F$, was highly upregulated in ATII cells but not in primary fibroblasts obtained from IPF patients (Figure 6C). Consistently, WISP1 localized to hyperplastic, proliferating ATII cells in close proximity to epithelial lesions and fibroblast foci in IPF (Figure 6D; for antibody control, see Supplemental Figure 4), as assessed by staining of WISP1 and phospho-histone H3 in serial sections. WISP1 protein expression was increased in tissue samples from IPF patients, as determined by Western blot analysis (Figure 
A
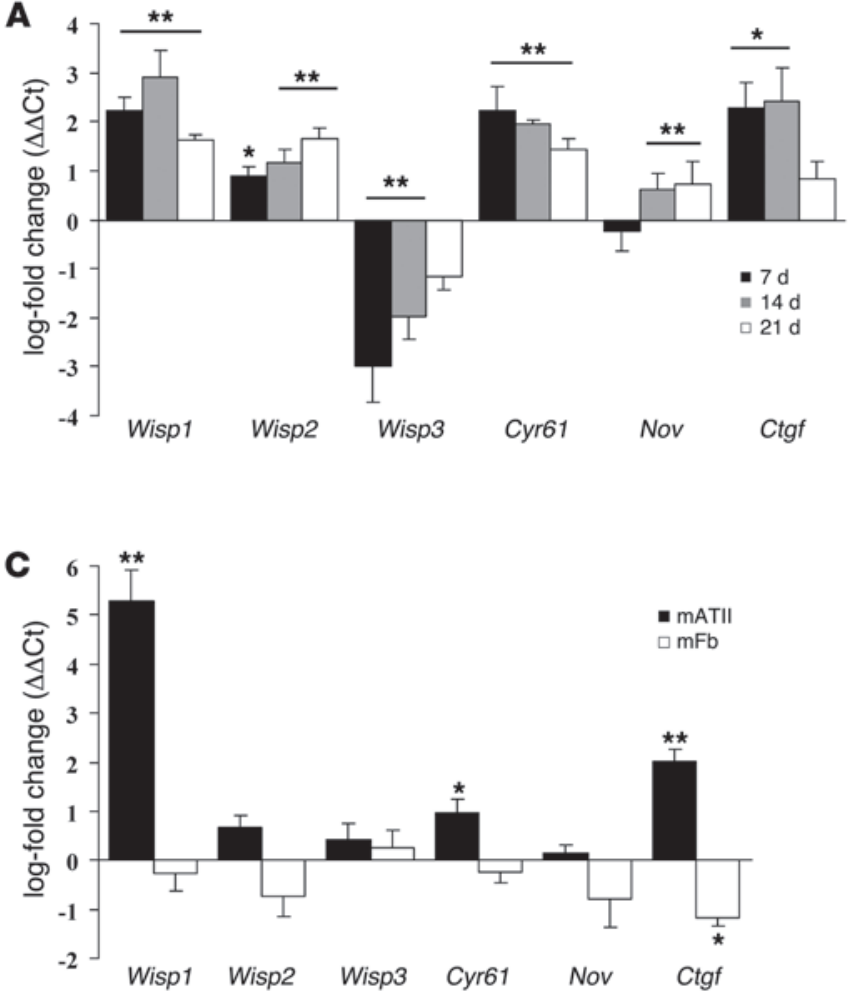

B
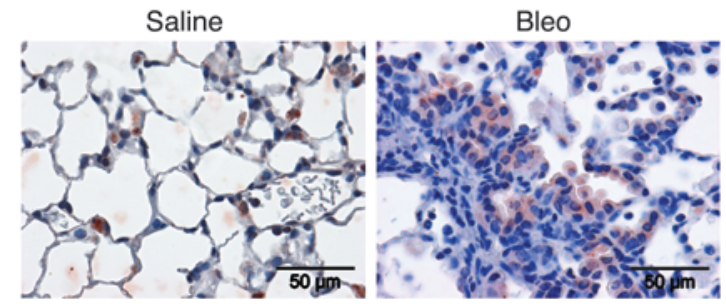

Saline

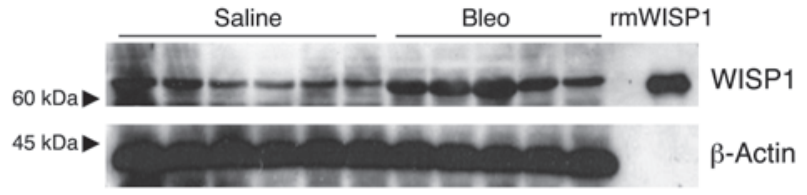

D

Saline
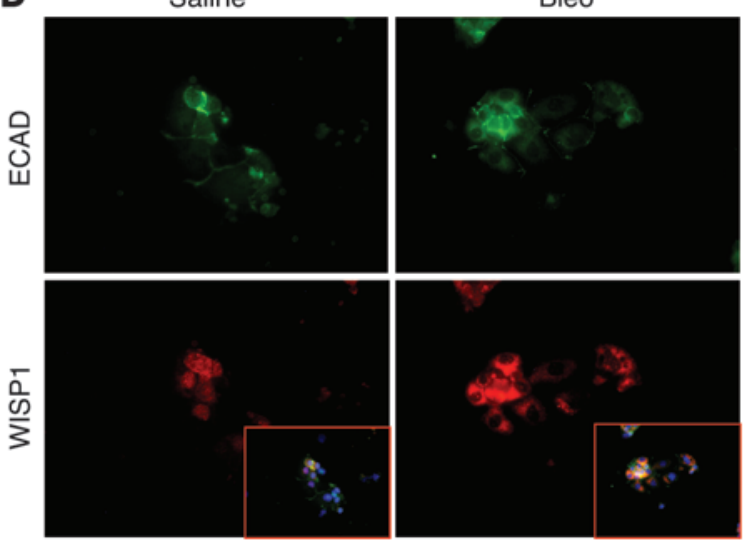

\section{Figure 5}

Increased WISP1 expression in ATII cells in vitro and in vivo in experimental lung fibrosis. (A) Time-course analysis of CCN family member gene expression was performed using qRT-PCR of lung homogenates harvested 7, 14, or 21 days after administration of bleomycin. Respective mRNA levels were plotted as log-fold change $(\Delta \Delta \mathrm{Ct})$ of mRNA levels in bleomycin- versus time-matched saline-treated mice $(n=4)$ and are presented as mean \pm SEM. (B) WISP1 protein expression was assessed using immunohistochemical staining of whole-lung sections of bleomycin- or saline-treated mice 14 days after application (upper panels) and Western blot analysis in total protein lysates (lower panels). Recombinant mouse WISP1 protein served as a positive control; $\beta$-actin served as a loading control. Data are representative of at least 2 independent experiments using 6 (Saline) or 5 (Bleo) different lung tissues each. (C) The mRNA levels of all CCN family members were determined by qRT-PCR in primary ATII cells (black bars, $n=6$ ) or primary mouse fibroblasts ( $\mathrm{mFb}$; white bars, $n=4)$ isolated from the lungs of saline- or bleomycin-treated mice 14 days after administration. Results are plotted as log-fold change $(\Delta \Delta \mathrm{Ct})$ of mRNA levels in bleomycin-derived versus saline-derived cells and are presented as mean \pm SEM. (D) WISP1 protein expression was assessed using double immunostaining for ECAD (green) and WISP1 (red) of primary ATII cells from saline- or bleomycin-treated mice, respectively (original magnification, $\times 40$ ). Nuclei were visualized by DAPI staining (inset; original magnification, $\times 40$ ). Data are representative of at least 3 independent experiments. ${ }^{*} P<0.05,{ }^{* \star} P<0.02$.

6E). Importantly, increased expression of WISP1 was specific for IPF, whereas in other lung disorders, such as nonspecific interstitial pneumonia (NSIP) and chronic obstructive pulmonary disease (COPD), no regulation of WISP1 mRNA was observed (Figure 6F).

Increased ATII cell proliferation and profibrotic marker release in response to WISP1. To begin to delineate the functional contribution of WISP1, we next assessed the effect of recombinant WISP1 on ATII cells. WISP1 treatment exerted a strong proliferative effect on primary ATII cells (154\%-220\%, 95\% CI), which was more pronounced than that of CTGF or keratinocyte growth factor (KGF) (Figure 7, A and B). Similarly, WISP1 treatment led to increased proliferation of A549 cells (Supplemental Figure 5A). In contrast, ATII cells obtained from bleomycin-treated animals were not responsive to WISP1 stimulation (bleomycin, 186\%-213\% vs. bleomycin plus WISP1, 199\%-215\%) (Figure 7A). Since these cells secreted higher amounts of WISP1 (Figure 5), thereby driving a proliferative response, we sought to neutralize WISP1 using 2 different approaches: As depicted in Figure 7C, WISP1 antagonism using neutralizing antibodies attenuated the increased baseline proliferation of fibrotic ATII cells (bleomycin plus $\alpha$-WISP1, $103 \%-148 \%$ ). Second, these results were confirmed using an siRNA against Wisp1 (mRNA and protein knockdown efficiency are shown in Supplemental Figure 5, B and C). The knockdown of Wisp1 led to decreased proliferation of primary ATII cells isolated from bleomycin- and saline-treated mouse lungs, as analyzed by cell counting (Figure 7D) and $\left[{ }^{3} \mathrm{H}\right]$ thymidine incorporation (Supplemental Figure 5D), respectively.

EMT in response to WISP1. EMT is the reversible phenotypic switching of epithelial to fibroblast-like cells and has recently gained recognition as a possible mechanism underlying the increase in the (myo)fibroblast pool that occurs in pulmonary fibrosis $(29,30)$. It has been demonstrated that TGF- $\beta$ represents a main inducer and 


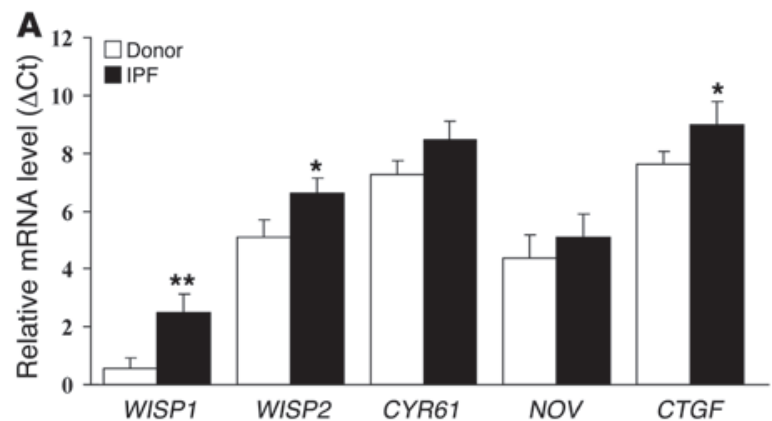

B

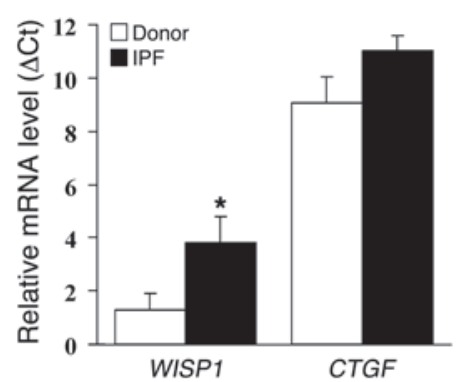

E

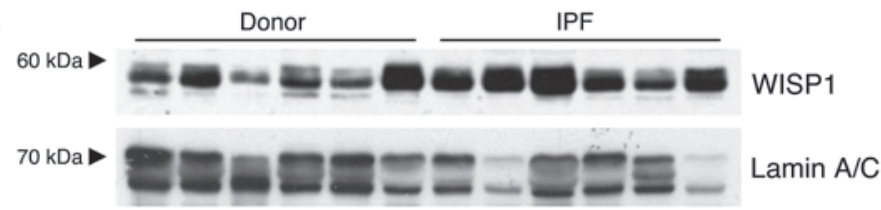

$\mathbf{F}$

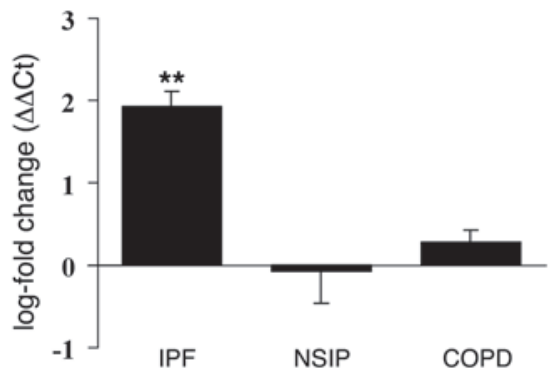

C

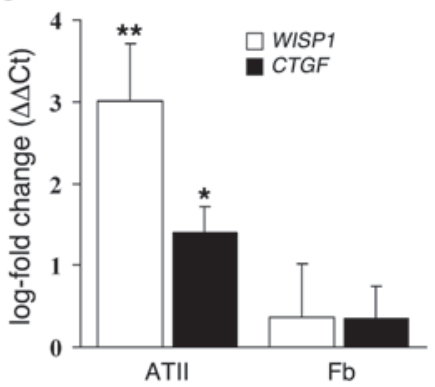

D
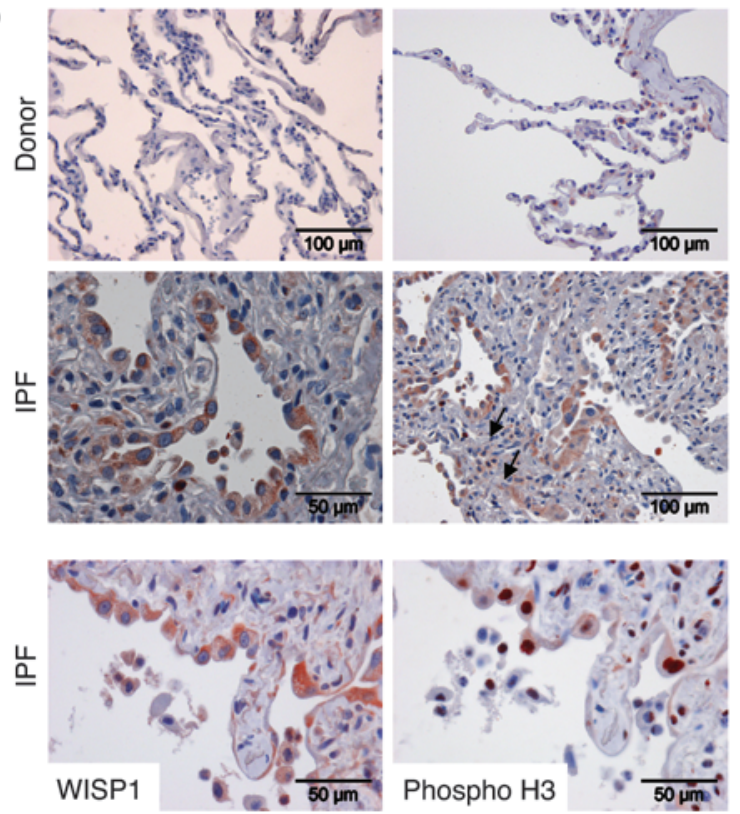

\section{Figure 6}

Increased WISP1 expression in ATII cells in vitro and in vivo in IPF. (A) mRNA levels of the CCN family members were analyzed by qRT-PCR using lung homogenates derived from donor or IPF lung explants $(n=10$ each). (B) mRNA levels of WISP1 and CTGF were analyzed by qRTPCR in microdissected septae from donor or IPF lungs ( $n=5$ each). Results in $\mathbf{A}$ and $\mathbf{B}$ are plotted as relative mRNA levels ( $\triangle$ Ct) and presented as mean \pm SEM. (C) mRNA levels of WISP1 (white bars) and CTGF (black bars) were determined by qRT-PCR in primary human ATII cells $(n=4)$ or fibroblasts $(n=3)$ isolated from donor or IPF lung tissue. Results are plotted as log-fold increase $(\Delta \Delta C t)$ of mRNA levels in IPF-derived versus donor-derived cells and presented as mean \pm SEM. (D) WISP1 protein expression in sections from control or IPF lung specimens was assessed by immunohistochemistry. Arrows indicate extracellular WISP1 staining. WISP1 and phospho-histone H3 (Phospho H3) protein expression in serial whole-lung sections from IPF patients was assessed by immunohistochemistry (bottom row). Data are representative of at least 2 independent experiments using at least 4 different lung tissues from IPF specimens. (E) WISP1 protein expression was determined in total protein lysates from donor or IPF lung tissue using Western blot analysis. Lamin A/C was used as a loading control. Data are representative of at least 2 independent experiments using 6 different lung tissues for donor and IPF specimens. (F) mRNA levels of WISP1 were analyzed by qRT-PCR using lung homogenates derived from IPF $(n=6)$, nonspecific interstitial pneumonia (NSIP; $n=4)$, or chronic obstructive pulmonary disease (COPD; $n=6$ ) lung explants. Results are plotted as log-fold increase $(\Delta \Delta \mathrm{Ct})$, compared with control lungs (transplant donor), and are presented as mean \pm SEM. ${ }^{\star} P<0.05$, ${ }^{\star \star} P<0.02$.

regulator of EMT in multiple organ systems $(30,31)$, but little is known about other cytokines or mediators that are able to induce EMT during lung fibrosis. Here, we show that WISP1 treatment of primary ATII cells led to decreased mRNA levels of Tjp1, Cdh1, and Ocln but elevated mRNA levels of Fsp1 an Acta2, as analyzed by qRTPCR, indicating that WISP1 is a potent inducer of EMT in ATII cells in vitro (Figure 8A). The induction of EMT was corroborated by immunofluorescence staining, which revealed an increase in $\alpha$-SMA-positive cells (Figure 8B, left panel), as well as $\alpha$-SMA and TJP1 double-positive cells (mesenchymal and epithelial markers, respectively; Figure 3B, middle panel, and Supplemental Figure 6) in response to WISP1. This was abrogated by neutralizing antibodies against WISP1 (Figure 8B, right panel, and Supplemental Figure 6). Furthermore, treatment with WISP1 led to enhanced migration of ATII cells, which is associated with the process of EMT (Figure 8C). WISP1 treatment of ATII cells rapidly induced the expression of promigratory genes, such as $M m p 7$ and $M m p 9$, as well as the previously identified mediators in pulmonary fibrosis Pai1 and Spp1 (Figure 8D). This strongly suggests that WISP1 not only is causally involved in ATII cell hyperplasia but also induces increased expres- 
A
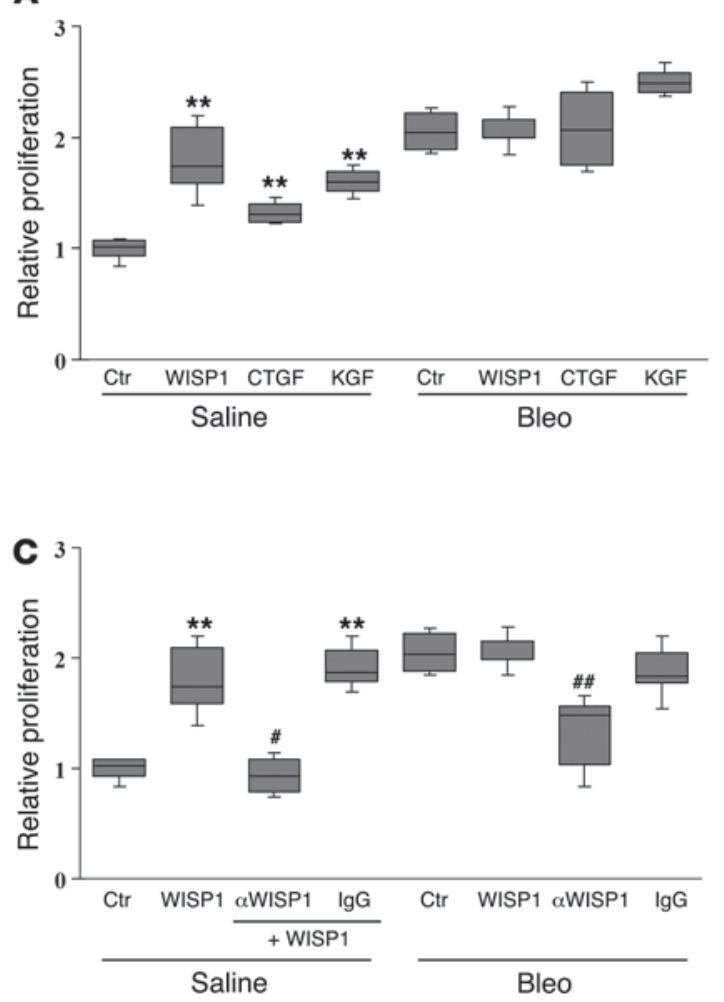

B
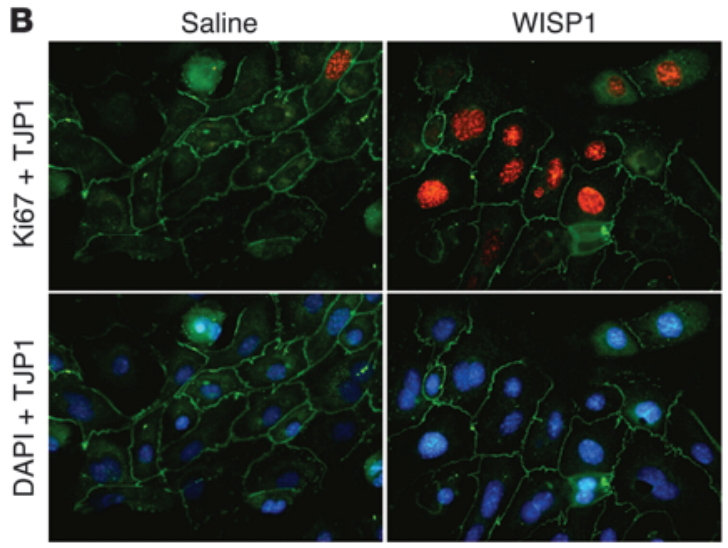

D

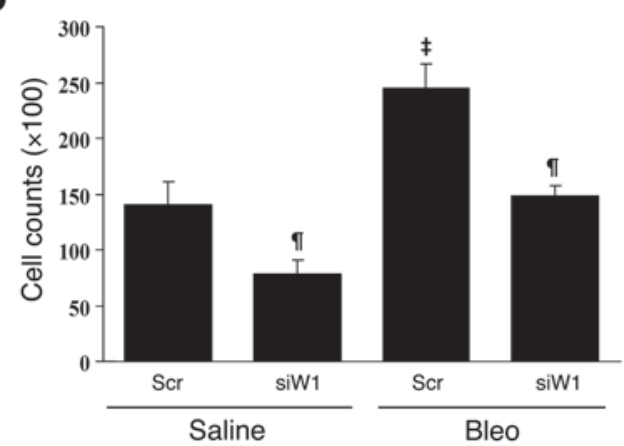

Figure 7

Increased ATII cell proliferation in response to WISP1. (A) The effects of WISP1 ( $1 \mu \mathrm{g} / \mathrm{ml})$, CTGF $(2.5 \mathrm{ng} / \mathrm{ml})$, or keratinocyte growth factor $(\mathrm{KGF} ; 10 \mathrm{ng} / \mathrm{ml})$ on primary mouse ATII cell proliferation were assessed by $\left[{ }^{3} \mathrm{H}\right]$ thymidine incorporation and presented as relative proliferation, compared with unstimulated ATII cells isolated from saline-treated mice (control [Ctr]) $(n=10)$; ${ }^{\star *} P<0.02$. (B) The effect of WISP1 (1 $\mu \mathrm{g} / \mathrm{ml}, 24$ hours) on the proliferation of primary ATII cells was assessed by coimmunostaining of Ki67 (red) and TJP1 (green) (original magnification, $\times 40$ ). Nuclei were visualized by DAPI staining (blue). (C) The effects of neutralizing $\alpha$-WISP1 antibodies $(20 \mu \mathrm{g} / \mathrm{ml} \alpha$-WISP 1$)$ or preimmune serum (IgG control), each applied 30 minutes prior to the addition of WISP1, were analyzed by $\left[{ }^{3} \mathrm{H}\right]$ thymidine incorporation. Data are presented as relative proliferation, compared with unstimulated ATII cells isolated from saline-treated mice $(n=5)$; ${ }^{*} P<0.02$ versus control; $\# P<0.02$ versus WISP1 stimulation; \#\# $P<0.02$ versus control Bleo. (D) Proliferation of ATIl cells subjected to scrambled (Scr) or Wisp1 siRNA (siW1) treatment (150 $\mathrm{nM}$ each) was assessed by cell counting 24 hours after treatment. Data are presented as mean $\pm \mathrm{SEM} ; \pm P<0.02$, Bleo versus saline; ${ }^{\mathbb{}} P<0.02$, siRNA versus scrambled. The efficiency and specificity of WISP1 knockdown by siRNA treatment were investigated by qRT-PCR and Western blot analysis (see Supplemental Figure 5, B and C).

sion and secretion of profibrotic mediators, thereby perpetuating the process of lung fibrosis. Finally, the potential of ATII cells to undergo EMT in vivo was supported by qRT-PCR analysis of freshly isolated ATII cells, which revealed a gain of mesenchymal marker expression and a loss in epithelial cell marker expression in ATII cells isolated from fibrotic mouse lungs (Figure 8E).

Enhanced myofibroblast activation and ECM deposition in response to WISP1. Disturbed epithelial-mesenchymal crosstalk is a hallmark of lung fibrosis $(3,12)$. We therefore next assessed the effects of WISP1 on lung fibroblasts, the key effector cell type in lung fibrosis. WISP1 treatment led to a significant induction of the ECM components type I collagen $\alpha 1$ (Col1a1) and fibronectin 1 (Fn1), as well as (myo)fibroblast activation markers in NIH 3 T3 cells (Figure 9A) and human lung fibroblasts (Figure 9D), as assessed by qRT-PCR of WISP1- and vehicle-treated fibroblasts. Further, WISP1 treatment resulted in a marked increase in collagen production by fibroblasts in vitro (Figure 9, B and E). Moreover, collagen production was similar in WISP1- and TGF- $\beta 1$-treated cells $(219 \% \pm 42 \%$ vs. $184 \% \pm 45 \%$ for NIH 3 T3 fibroblasts and
$238 \% \pm 14 \%$ vs. $195 \% \pm 11 \%$ for human lung fibroblasts, respectively). This was confirmed by immunofluorescence staining of type I collagen in fibroblasts, which demonstrated increased collagen staining in response to WISP1 (Figure 9C). Interestingly, the proliferation of fibroblasts was not affected by WISP1 treatment, independent of serum conditions (Supplemental Figure 7).

In sum, these findings suggest that WISP1 also exerts paracrine effects on lung fibroblasts, further contributing to its profibrotic action and demonstrating its relevance to IPF pathogenesis.

Attenuation of lung fibrosis in vivo by WISP1 inhibition. To assess whether modulation of WISP1 activity represents an effective therapeutic option in lung fibrosis, we depleted WISP1 during bleomycin-induced lung fibrosis using antibodies shown to be effective in neutralizing WISP1 activity (Figure 7C). To this end, we subjected mice to bleomycin-induced lung fibrosis and treated them with repetitive orotracheal applications of $\alpha$-WISP1 or species-matched preimmune control antibodies. As depicted in Figure 10, mice subjected to WISP1 neutralization exhibited significantly less pulmonary fibrosis and a marked decrease in ECM deposition, as assessed 
A

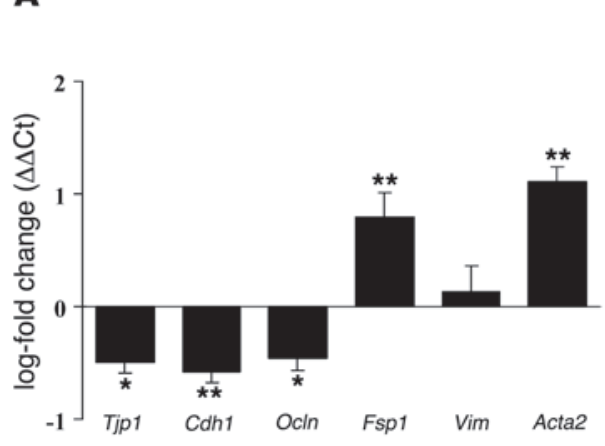

B
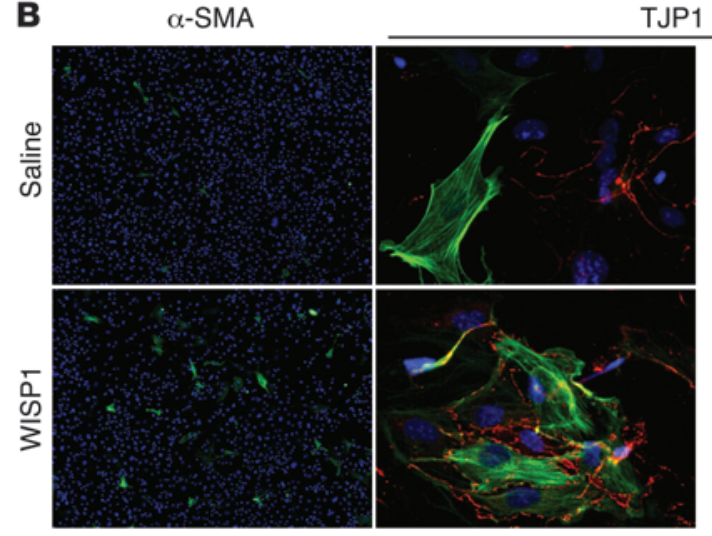

TJP1 $+\alpha-$ SMA

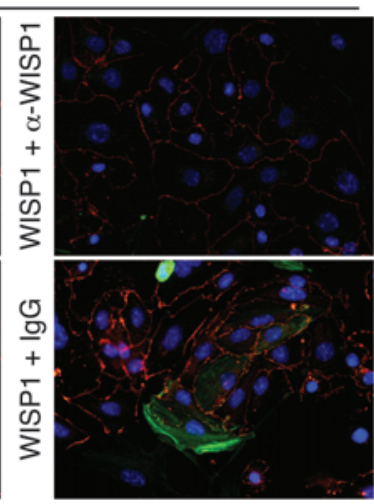

E

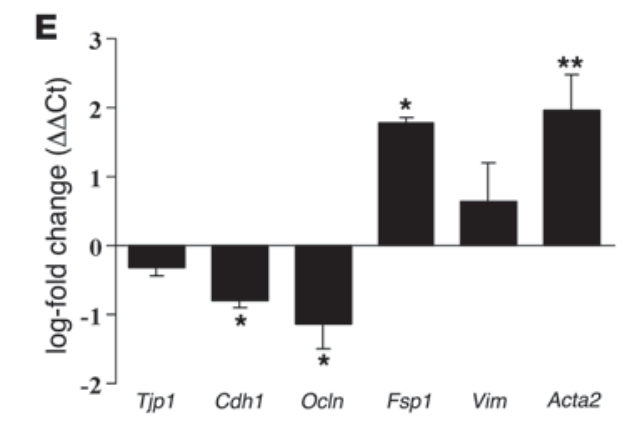

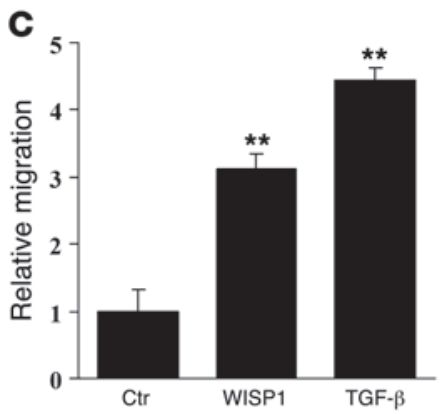

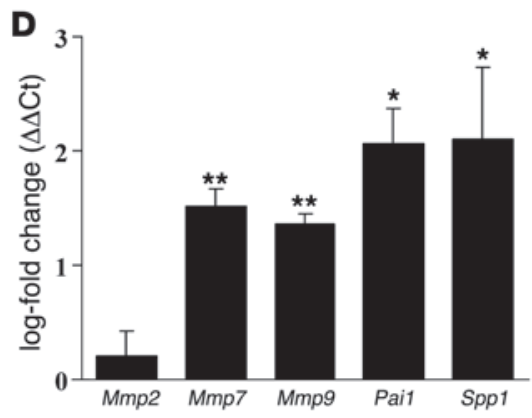

\section{Figure 8}

EMT of ATII cells in response to WISP1. (A) Primary mouse ATII cells were stimulated with WISP1 ( $1 \mu \mathrm{g} / \mathrm{ml}, 12$ hours), and the mRNA levels of the EMT marker genes Tjp1, Cdh1, Ocln, Fsp1, Vim, and Acta2 were analyzed by qRT-PCR ( $n=5$ for each). (B) Primary ATII cells were stimulated with WISP1 $(1 \mu \mathrm{g} / \mathrm{ml}, 12$ hours) in the absence or presence of neutralizing $\alpha$-WISP1 antibodies or preimmune serum (IgG control). EMT was assessed by immunofluorescence detection of $\alpha$-SMA expression (left panels, original magnification, $\times 10$ ) and colocalization of $\alpha$-SMA (green) and TJP1 (red) (middle and right panels; original magnification, $\times 40$ ). Nuclei were visualized by DAPI staining. (C) The migration of ATII cells in response to WISP1 was determined in a Boyden chamber assay; TGF- $\beta 1(2 \mathrm{ng} / \mathrm{ml})$ was used as a positive control. Data are presented as the mean \pm SEM of 2 independent experiments performed in triplicate. (D) Primary ATIl cells were stimulated with WISP1 (1 $\mu \mathrm{g} / \mathrm{ml}, 12 \mathrm{hours}$ ), and the mRNA levels of the metalloproteinases Mmp2, Mmp7, and Mmp9 and the profibrotic marker genes Pai1 and Spp1 were analyzed by qRT-PCR ( $n=5$ for each) and plotted as log-fold increase $(\Delta \Delta \mathrm{Ct})$ of mRNA levels in WISP1-stimulated versus unstimulated cells. (E) The mRNA levels of the EMT marker genes Tjp1, Cdh1, Ocln, Fsp1, Vim, and Acta2 were determined by qRT-PCR in primary ATII cells isolated from salineor bleomycin-treated mice 14 days after administration $(n=6)$. All qRT-PCR results are presented as mean \pm SEM. ${ }^{* *} P<0.02,{ }^{*} P<0.05$.

by immunohistochemistry for type 1 collagen (Figure 10A), quantification of total lung collagen (bleomycin plus IgG, $295 \% \pm 17 \%$ vs. bleomycin plus $\alpha$-WISP1, $160 \% \pm 31 \%$, compared with saline-treated controls) (Figure 10B), as well as $\alpha$-SMA and tenascin C immunostaining (Figure 10C and Supplemental Figure 8, respectively).

These findings were corroborated by the finding that WISP1 neutralization also led to decreased mRNA expression of the profibrotic markers Col1a1, Spp1, Mmp7, and Pai1 (Figure 11B and Supplemental Figure 9A), which is of significance, as we have shown that WISP1 induces the expression of these markers in primary ATII cells (Figure 8D). In addition, WISP1 neutralization resulted in a reversal of EMT marker gene expression in vivo (Figure $11 \mathrm{C}$ and Supplemental Figure 9B), which were induced by WISP1 in vitro (Figure $8 \mathrm{~A}$ ). Interestingly, WISP1 neutralization led to a marked decrease in ECM deposition but did affect inflammatory cell influx in response to bleomycin (Figure 11A, right panels).

Finally, WISP1 neutralization partially restored normal lung function, as assessed by lung compliance measurements (bleomycin plus IgG, $0.065 \pm 0.073 \mathrm{ml} / \mathrm{kPa}$ vs. bleomycin plus $\alpha$-WISP1, $0.09 \pm 0.11 \mathrm{ml} / \mathrm{kPa}$, 95\% CI; Figure 11D). Most importantly, WISP1 neutralization significantly improved the survival of bleomycin- challenged mice (bleomycin plus IgG, 47\% vs. bleomycin plus $\alpha$-WISP1, 74\%; $n=18$ for each) (Figure 11E), suggesting a valuable novel approach for the treatment of lung fibrosis.

\section{Discussion}

In the current study, we identify WISP1, a member of the CCN family of secreted cysteine-rich matricellular proteins, as a mediator of disturbed epithelial-mesenchymal crosstalk in lung fibrosis that represents a potential therapeutic target in this disease. We demonstrate that WISP1 was highly expressed in hyperplastic ATII cells, mediated enhanced ATII cell proliferation, and induced profibrotic marker gene expression in ATII cells. In addition, WISP1 enhanced fibrogenesis by inducing EMT of ATII cells and increasing collagen production by fibroblasts, indicating that WISP1 exerts its profibrotic effects by a multitude of autocrine and paracrine effects in the lung (Figure 12). Most importantly, neutralization of WISP1 resulted in marked attenuation of bleomycin-induced lung fibrosis.

These findings are of special interest, as the prognosis for individuals with IPF is poor due to unresponsiveness to currently available therapies. IPF is the most common of the IIPs, which all exhibit distortion of normal tissue architecture and a loss of lung 
A

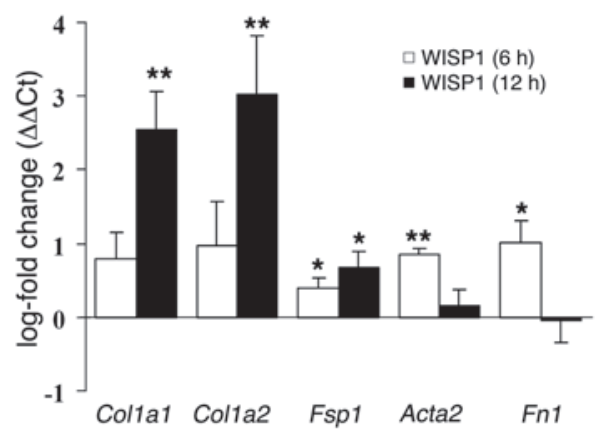

B

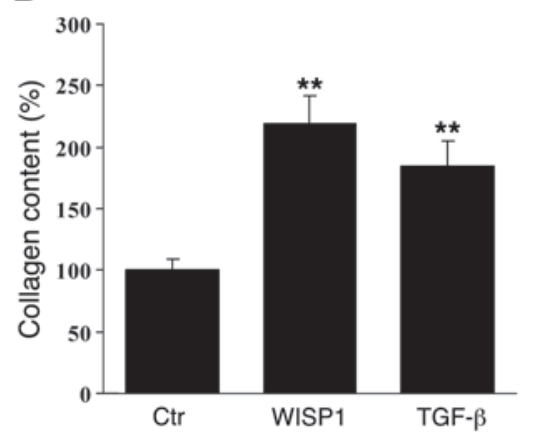

C

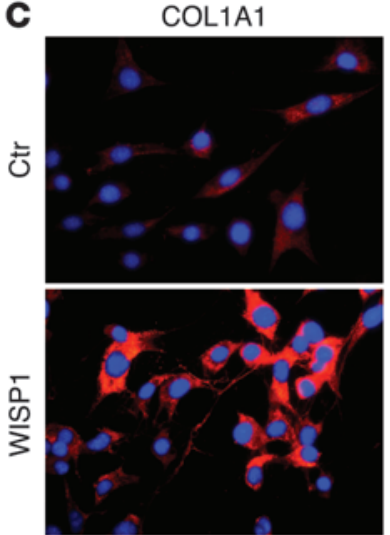

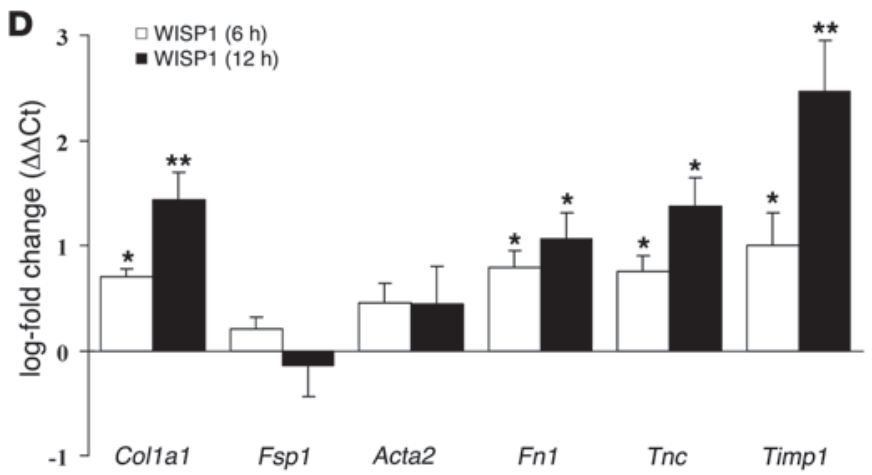

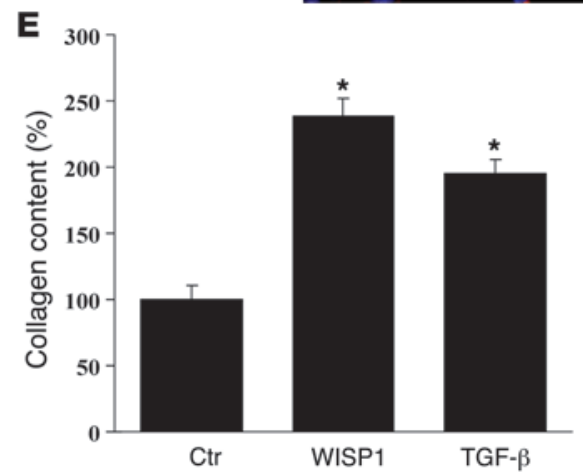

Figure 9

Enhanced ECM deposition and myofibroblast marker expression by fibroblasts in response to WISP1. (A) NIH 3T3 fibroblasts were stimulated with WISP1 (1 $\mu \mathrm{g} / \mathrm{ml} ; 6$ or 12 hours, as indicated), and the mRNA levels of the ECM components Col1a1, Col1a2, fibronectin (Fn1), and the (myo)fibroblast activation markers Fsp1 and Acta2 were analyzed by qRT-PCR $(n=4)$. Results are plotted as log-fold increase $(\Delta \Delta C t)$ of mRNA levels in WISP1-stimulated versus unstimulated cells and presented as mean \pm SEM. (B) NIH 3T3 fibroblasts were stimulated with WISP1 $(1 \mu \mathrm{g} / \mathrm{ml})$ or TGF- $\beta 1$ ( $2 \mathrm{ng} / \mathrm{ml})$ for 24 hours, and total collagen content was quantified using the Sircol collagen assay $(n=6)$. (C) Fibroblast collagen expression and localization after WISP1 stimulation for 24 hours were assessed by immunofluorescence detection of type I collagen 1 (red). Nuclei were visualized by DAPI staining (blue). Data are representative for at least 3 independent experiments. Original magnification, $\times 40$. (D) Human lung fibroblasts were stimulated with WISP1 $(1 \mu \mathrm{g} / \mathrm{ml} ; 6$ or 12 hours, as indicated), and the mRNA levels of the ECM components Col1a1, fibronectin ( $F n 1$ ), the (myo)fibroblast activation markers Fsp1, Acta2, tenascin C (Tnc), and the tissue inhibitor of matrix metalloproteinases 1 (Timp1) were analyzed by qRT-PCR $(n=3)$ as described in A. (E) Human lung fibroblasts were stimulated with WISP1 (1 $\mu \mathrm{g} / \mathrm{ml})$ or TGF- $\beta 1$ $(2 \mathrm{ng} / \mathrm{ml})$ for 24 hours, and total collagen content was quantified using the Sircol collagen assay $(n=3) .{ }^{\star} P<0.05,{ }^{\star *} P<0.02$.

function $(2,32)$. This fibrotic tissue transformation is characterized by an increase in total lung collagen levels, with the inability of the lung to properly conduct gas exchange. While historically, inflammatory processes were thought to trigger and facilitate the progression of IPF (32), this view has recently been questioned, primarily due to the ineffectiveness of antiinflammatory therapy in $\operatorname{IPF}(3,33)$. A major key pathophysiological event in IPF that is currently under discussion is repetitive alveolar epithelial cell stimulation and injury without appropriate repair and subsequent fibroblast activation $(3,6)$.

At the onset of our studies, we sought to define alterations in the phenotype and gene expression profile of ATII cells that may initiate and perpetuate the progression of lung fibrosis. The findings that ATII cells from fibrotic lungs exhibited an increased proliferative capacity and enhanced gene expression of proliferative mediators indicated to us that ATII cell proliferation is a dominant pathophysiologic mechanism after initial injury in experimental lung fibrosis. Indeed, injury and apoptosis within the alveolar epithelium, with subsequent ATII cell hyperplasia, are consistent findings in experimental and human lung fibrosis.
For example, it has been shown that epithelial apoptosis occurs in experimental lung fibrosis (34-36) and human IPF lungs (37-40), but a causality between apoptosis and the fibrogenic process has not been clearly established $(12,41)$. Epithelial hyperplasia and proliferation are reported in both experimental lung fibrosis (42, 43) and IPF (44-46). Ultrastructural studies have revealed the existence of proliferative alveolar epithelial cells immediately adjacent to injured epithelial cells (47-49), suggesting that epithelial apoptosis and proliferation and hyperplasia occur simultaneously during the process of fibrosis.

One of the most important decisions following a microarray screen of diseased tissues/cells is the choice of the gene of interest for functional intervention studies. Of all genes differentially expressed in fibrotic ATII cells, we focused our study on further delineating WISP1 function in lung fibrosis for the following reasons: First, WISP1 is reported to be a WNT target, and WNT signaling is essential to organ development, a process that is recapitulated in organ failure $(24,50,51)$. Second, we and others demonstrated that the $\mathrm{WNT} / \beta$-catenin pathway is expressed and operative in adult lung epithelium in $\operatorname{IPF}(25,26)$. Third, we provided 
A

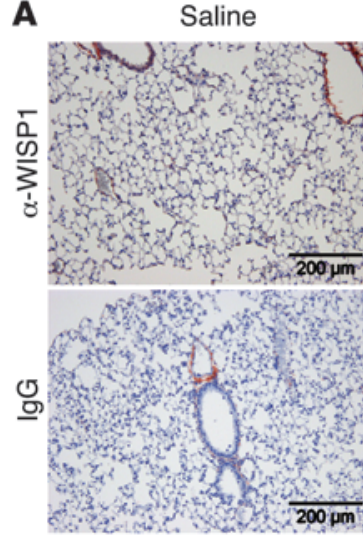

B

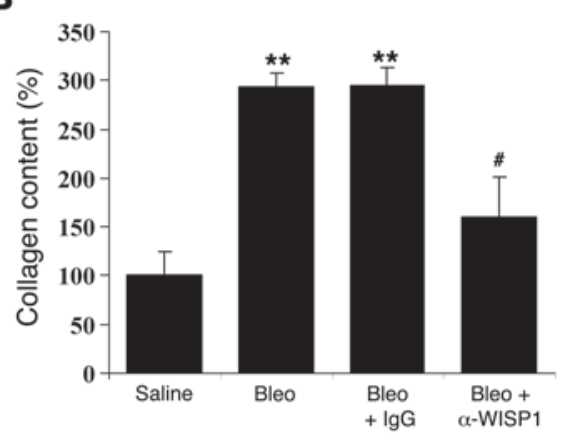

Bleo

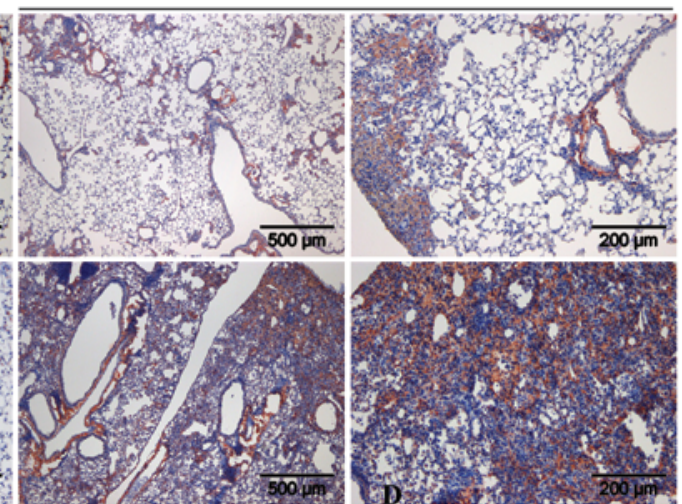

C

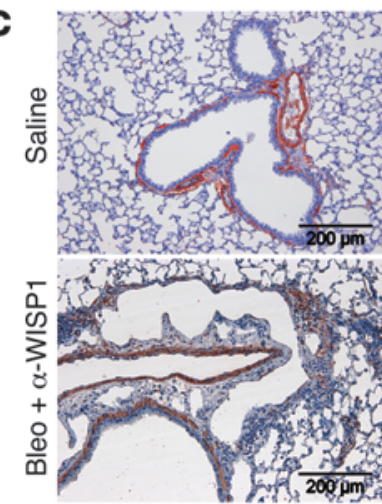

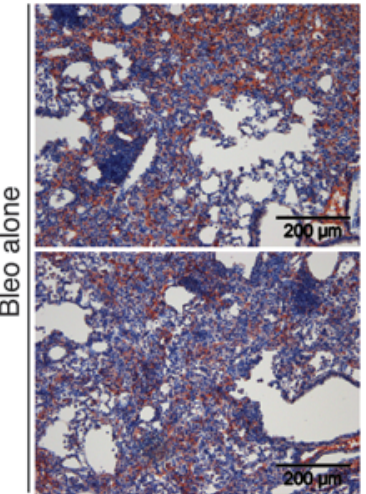

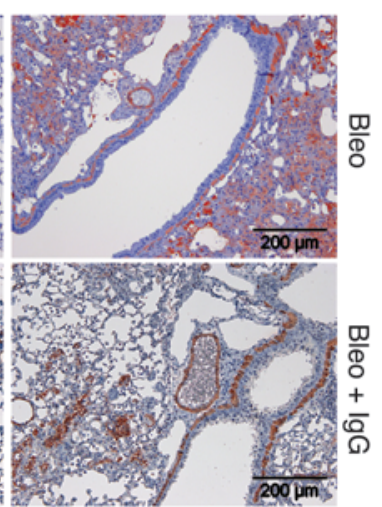

Figure 10

WISP1 neutralization in vivo leads to the attenuation of lung fibrosis. (A) Mice were subjected to saline or bleomycin instillation, as described above, and treated either with neutralizing $\alpha$-WISP1 antibodies or preimmune serum (IgG control) by orotracheal application as described in detail in Methods. Lungs were processed 14 days after bleomycin application for immunohistochemical analysis and stained for type I collagen. (B) Total collagen content in lung homogenates was quantified using the Sircol collagen assay. Results are derived from whole lungs harvested 14 days after saline, bleomycin, bleomycin plus preimmune serum (IgG control), or bleomycin plus neutralizing $\alpha$-WISP1 antibody instillation by orotracheal application ( $n=5$ each). Results are presented as mean $\pm \mathrm{SEM}$; ${ }^{* \star} P<0.02,{ }^{\sharp} P<0.02$ versus Bleo + IgG treatment. (C) Indicated lung sections were used for immunohistochemical analysis and stained with $\alpha$-SMA. Pictures are representative of at least 2 independent experiments using at least 4 different lung tissues for each condition.

evidence that the WNT/ $\beta$-catenin pathway is activated in epithelial cells during the development of experimental lung fibrosis. Fourth, WISP1 regulation was previously reported in microarray lists derived from IPF lung homogenates, indicating that WISP1 is consistently upregulated in IPF lung tissues from different cohorts $(17,19)$. Notably, Selman and colleagues also identified WISP1 to be regulated in a microarray analysis comparing IPF specimen with hypersensitivity pneumonitis (17). Fifth, increased WISP1 expression has been shown to be causally involved in epithelial cell hyperplasia in breast cancer cell lines (52). Finally, recent evidence has suggested that WISP1 exhibited antiapoptotic and proliferative effects on epithelial as well as mesenchymal cell lines $(53,54)$ and its mRNA expression is associated with lung cancer (55).

In our current study, we present in vitro and in vivo evidence demonstrating that WISP1 acts as a proliferative mediator of ATII cells in vitro and localizes to hyperplastic ATII cells in vivo. These data are in agreement with recent reports showing a proliferative effect of WISP1 on epithelial cell lines $(52,56)$. Further, we showed that WISP1 acted in an autocrine fashion by increasing the release of profibrotic cytokines from the alveolar epithelium, including SPP1, MMP7, MMP9, and PAI1. In particular, MMP7 has recently been assigned a key role in pulmonary fibrosis and shown to be expressed in ATII cells $(57,58)$. In this study, we demonstrated that expression of MMP7, along with SPP1, PAI1, and MMP9, is induced by WISP1, essentially suggesting that a plethora of profibrotic markers released from ATII cells in fibrosis are under transcriptional control of WISP1. Further studies are needed to reveal the distinct signaling pathways involved in WISP1-induced effects. In this respect, we observed the activation of the Akt kinase (data not shown), which is in line with previous data demonstrating Akt activation in response to WISP1 (53).

IPF is considered a disease of disturbed epithelial-mesenchymal crosstalk $(3,12)$, evidenced by the close proximity of hyperplastic and injured alveolar epithelial cells to fibroblast foci $(8,47)$. The pathological remodeling of lung tissue during disease pathogenesis of IPF can be dictated by direct cellular contact or, as described herein, the secretion of soluble mediators in an autocrine and/or paracrine fashion. WISP1 expression was increased in lung fibrosis, but its expression was regulated exclusively in alveolar epithelial cells, whereas we did not detect increased expression of either mRNA or protein in fibroblasts derived from experimental lung fibrosis or IPF lungs. Several findings, how- 

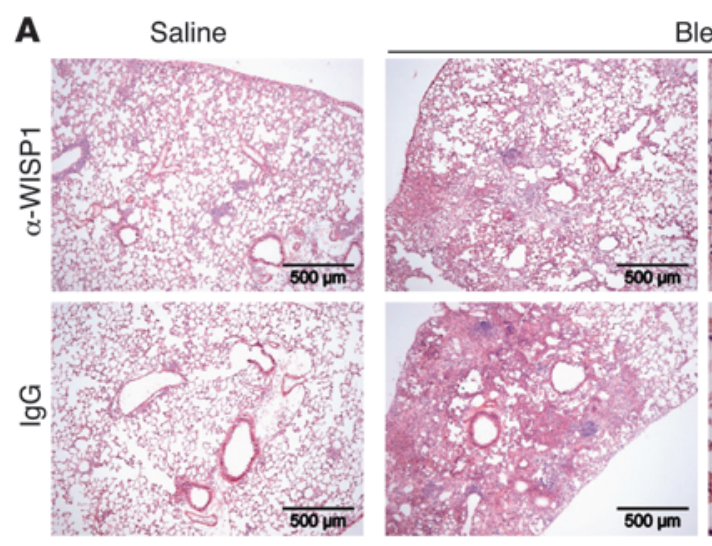

Bleo

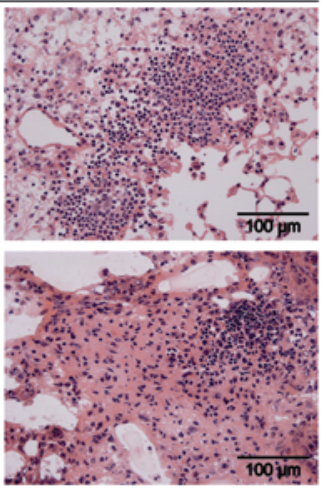

B

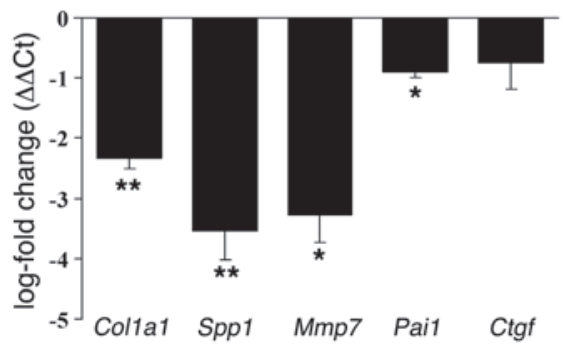

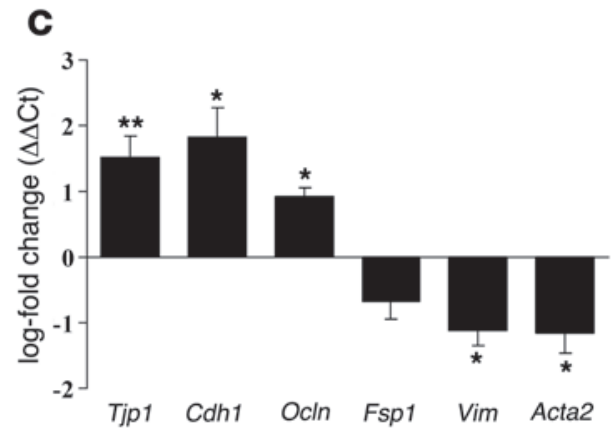
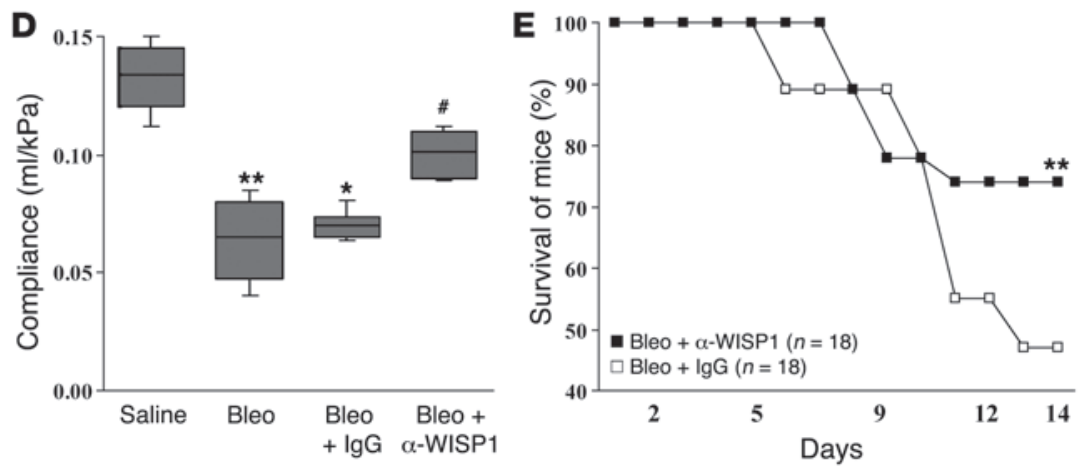

Figure 11

WISP1 inhibition in vivo leads to decreased profibrotic marker gene expression and increased survival in lung fibrosis. (A) Indicated lung sections were used for immunohistochemical analysis and stained with H\&E. (B and C) mRNA levels of the profibrotic marker genes Col1a1, Spp1, Mmp7, Pai1, and Ctgf (B) and the EMT marker genes Tjp1, Cdh1, Ocln, Fsp1, Vim, and Acta2 (C) were analyzed by qRT-PCR ( $n=5$ each). Results are plotted as log-fold change $(\Delta \Delta \mathrm{Ct})$ of mRNA levels in lung specimens 14 days after bleomycin instillation treated with neutralizing $\alpha$-WISP1 antibodies, compared with lungs treated with preimmune serum (IgG control). Results are presented as mean \pm SEM. See Supplemental Figure 9, A and B, for a comparison of all treatment groups. (D) Lung compliance measurements were obtained from mice instilled with saline, bleomycin, bleomycin plus IgG control, or bleomycin plus $\alpha$-WISP1 antibody ( $n=10$ for each), 14 days after initial exposure to bleomycin. (E) The survival of mice subjected to neutralizing $\alpha$-WISP1 or preimmune serum (IgG control) instillations $(n=18$ for each) was monitored. Days of antibody instillations are indicated on the $x$ axis. ${ }^{*} P<0.05$, ${ }^{* \star} P<0.02 ;{ }^{*} P<0.02$ versus Bleo $+\lg$ treatment.

ever, also support a paracrine effect of ATII cell-derived WISP1 on interstitial fibroblasts. We demonstrated that WISP1 led to increased expression of (myo)fibroblast activation markers and deposition of ECM molecules. While we did not observed an influence of WISP1 on fibroblast proliferation, a recent publication by Colston et al. (54) demonstrated a proproliferative effect of WISP1 on cardiac fibroblasts, suggesting a role for WISP1 in the remodeling of myocardial infarction.

The hallmark lesions of IPF are fibroblast foci, which are sites featuring activated myofibroblasts, synthesizing and depositing a collagen-rich ECM. The number of $\alpha$-SMA-positive, activated (myo)fibroblasts is significantly increased in multiple forms of pulmonary fibrosis, including IPF, but their origin remains to be elucidated. Currently, 3 major theories attempt to explain the origin of interstitial fibroblasts. It has been demonstrated that resident pulmonary fibroblasts can be activated in response to fibrogenic cytokines and growth factors, thereby increasing the fibroblast pool via local fibroproliferation (15). In addition, several recent studies have shown that bone marrow-derived circulating fibrocytes traffic to the lung during experimental lung fibrosis and serve as progenitors for interstitial fibroblast (59-61). Third, it was recently proposed that ATII cells are capable of undergoing the process of EMT, the reversible process by which cells switch from an epithelial to a fibroblast-like phenotype, which is initiated by an alteration of the transcriptional and proteomic profile of ATII cells $(30,31,62)$. Here, we report that WISP1 led to EMT by regulation of marker gene expression and induction of ATII cell migration. As TGF- $\beta$ represents a main inducer of EMT in multiple organ systems $(29,30)$, further studies are needed to fully appreciate the mechanistic role of WISP1 in this context.

In summary, our study demonstrates disturbed epithelialmesenchymal crosstalk in IPF and suggests that the autocrine and paracrine effects of WISP1, a member of the CCN family of secreted, cysteine-rich regulatory proteins, can initiate and perpetuate the fibrotic process at the interface of ATII cells and interstitial fibroblasts in the lung (Figure 12). Whether WISP1 induces proliferation, EMT, and/or ECM deposition in vivo is most probably dictated by the ATII cell microenvironment in disease. While an intact subepithelial ECM may facilitate proliferation, a disrupted and/or perturbed ECM will facilitate EMT, as recently suggested in the case of TGF- $\beta$ (31). WISP1, a signaling molecule downstream of the WNT signaling pathway, has thus far not been assigned a role 

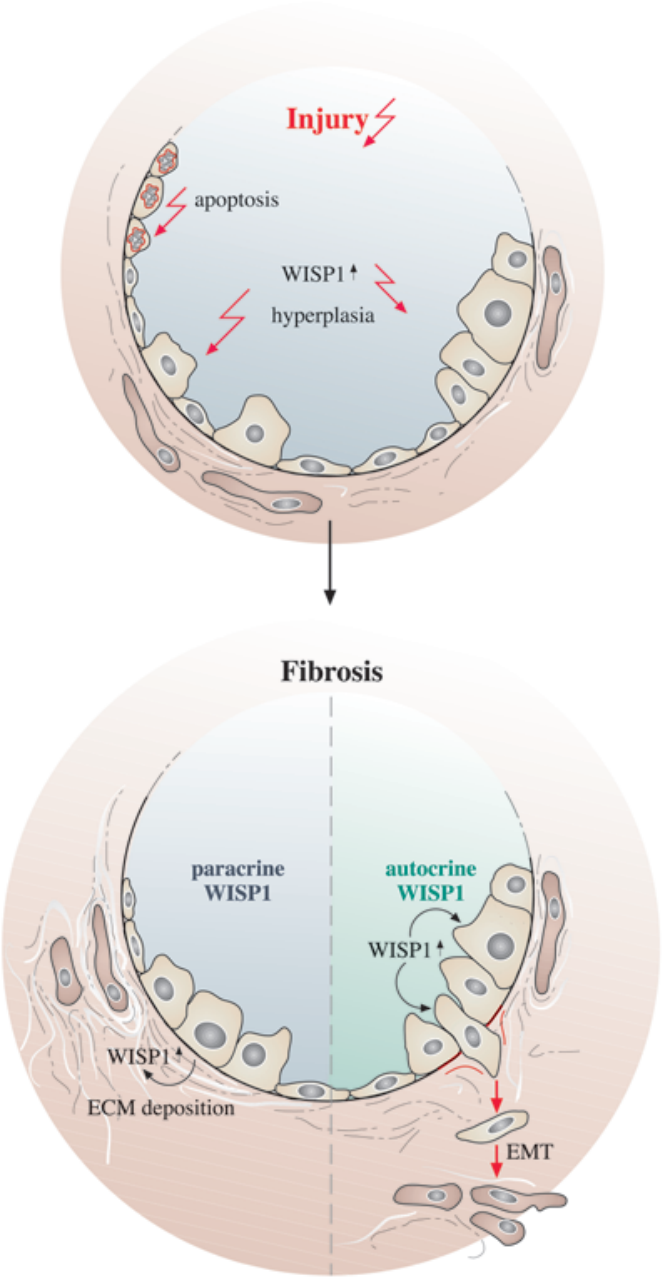

in pathologies of the lung. Recent evidence, however, suggested that the WNT pathway, which is critical during normal development and morphogenesis, is reactivated in IPF. Future work will undoubtedly shed more light on the molecular mechanisms of WISP1 signaling involved in IPF and reveal new therapeutic options for this disease.

\section{Methods}

Materials. Antibodies against SPC and $\alpha$-SMA were obtained from Chemicon (Millipore); panCK from Dako; TJP1 from Zymed (Invitrogen); $\alpha$-tubulin and lamin A/C from Santa Cruz Biotechnology Inc.; CD45, CD16/32, ECAD, and OCCL from BD Biosciences; and Ki67 from Invitrogen. Antibodies against total $\beta$-catenin, total GSK-3 $\beta$, and phospho-histone H3 were from Cell Signaling Technology; WNT1 and $\beta$-gal from Abcam; COL1A1 from Biodesign; and CCSP from Upstate (Millipore). Antibodies against WISP1 were purchased from R\&D Systems (AF 1680, MAB 1680, MAB 1627) and Abcam (ab60114). DMEM and FCS were obtained from Invitrogen. Recombinant WISP1, PDGF-BB, TGF- $\beta 1$, WNT3A, and CTGF was purchased from R\&D Systems. Recombinant KGF was a gift from Veronica Grau (University of Giessen).

Animals. Six- to 8 -week-old pathogen-free female C57BL/6N mice (Charles River Laboratories) were used throughout this study. All experiments were performed in accordance with the guidelines of the Ethics Committee of the University of Giessen School of Medicine and approved

\section{Figure 12}

The role of WISP1 in lung fibrosis. A proposed model depicting the role of WISP1 in lung fibrosis is shown. Initial injury leads to increased WISP1 expression by hyperplastic ATII cells, which sustains ATII cell hyperplasia. Fibrogenesis is then promoted via autocrine (lower right) or paracrine (lower left) effects on ATII cell mediator release and EMT and/or fibroblast ECM synthesis, respectively.

by the Regierungspräsidium Giessen, Hesse, Germany. Mice had free access to water and rodent laboratory chow. Bleomycin sulphate (Almirall) was dissolved in sterile saline solution and applied by MicroSprayer MS-IA-1C (Penn-Century) as a single dose of $0.08 \mathrm{mg}$ in $200 \mu \mathrm{l}$ saline solution per animal ( $\approx 5 \mathrm{U} / \mathrm{kg} \mathrm{BW})$. Control mice received $200 \mu \mathrm{l}$ saline. Lung tissues were excised and snap-frozen or inflated with $4 \%(\mathrm{~m} / \mathrm{v})$ paraformaldehyde in PBS (PAA Laboratories) at $21 \mathrm{cmH}_{2} \mathrm{O}$ pressure for histological analyses.

TOPGAL mice were purchased from The Jackson Laboratory. The derivation of TOPGAL mice has been described in detail previously (63). The following primers were used for identification of transgenic animals: Lac(Z)-F, 5'-GTTGCAGTGCACGGCAGATACACTTGCTGA-3'; Lac(Z)-R, 5'-GCCACTGGTGTGGGCCATAATTCAATTCGC-3'. Four- to 8-week-old mice were used for all experiments.

Alveolar epithelial cell isolation and culture. Primary ATII cells were isolated from saline- and bleomycin-treated mice as previously described (64). In brief, lungs were lavaged twice with $1 \mathrm{ml}$ sterile PBS and tissues digested with dispase and minced. The suspension was sequentially filtered through $100-, 20-$, and $10-\mu \mathrm{m}$ nylon meshes and centrifuged at $200 \mathrm{~g}$ for $10 \mathrm{~min}$ utes. The pellet was resuspended in DMEM, and negative selection for lymphocytes/macrophages was performed by incubation on CD16/32and CD45-coated Petri dishes for 30 minutes at $37^{\circ} \mathrm{C}$. Negative selection for fibroblasts was performed by adherence for 45 minutes on cell culture dishes. Cell purity and viability were analyzed in freshly isolated ATII cells directly after isolation. Cell purity was routinely assessed by epithelial cell morphology and immunofluorescence analysis with panCK and SPC (both positive) as well as $\alpha$-SMA and CD45 (both negative) of cytocentrifuge preparations of ATII cells. Cell viability was checked by trypan blue exclusion. ATII cells used throughout this study demonstrated $95 \% \pm 3 \%$ purity and greater than $97 \%$ viability. Finally, ATII cells were suspended in DMEM plus $10 \%$ FCS, 2 mM L-glutamine, $100 \mathrm{U} / \mathrm{ml}$ penicillin, and 100 $\mathrm{g} / \mathrm{ml}$ streptomycin and cultured for 24 hours to allow attachment. Phenotypic characterization was done after this time period. After media change, cells were cultured for a maximum of 2 days in a humidified atmosphere of $5 \% \mathrm{CO}_{2}$ at $37^{\circ} \mathrm{C}$.

Fibroblast isolation and culture. The NIH $3 \mathrm{~T} 3$ murine fibroblast cell line and human lung fibroblasts (HFL1) (German Collection of Microorganisms and Cell Cultures [DSMZ]), as well as primary lung fibroblasts isolated from bleomycin- or saline-treated mice were maintained in DMEM containing $10 \% \mathrm{FCS}$ and cultured in a humidified atmosphere of $5 \% \mathrm{CO}_{2}$ at $37^{\circ} \mathrm{C}$ as described previously $(64,65)$. Primary cells were used at passages 3 and 4 .

Human tissues. Lung tissue biopsy samples were obtained from 10 patients with IPF (UIP pattern; mean age, $51 \pm 11$ years; 4 females, 6 males), 4 patients with NSIP pattern (mean age, $55 \pm 5$ years; 2 females, 2 males), 6 patients with COPD (mean age, $54 \pm 4$ years; 4 females, 2 males), and 10 control subjects (organ donors; mean age, $48 \pm 14$ years; 5 females, 5 males). Samples were snap-frozen or placed in $4 \%(\mathrm{w} / \mathrm{v})$ paraformaldehyde immediately after explantation. Human ATII cells were isolated as previously described (66). The purity and viability of ATII cell preparations was assessed as described for mouse ATII cells and was consistently greater than $90 \%$ and greater than $95 \%$, respectively. Freshly isolated human ATII cells were used for gene expression analysis. The study protocol was approved by the Ethics 
Committee of the University of Giessen School of Medicine (AZ 31/93). Informed consent was obtained from each subject for the study protocol.

Laser-assisted microdissection. Microdissection was performed as described previously (67). In brief, 10- $\mu \mathrm{m}$ cryosections were mounted on glass slides, stained with hemalaun for 45 seconds, immersed in $70 \%$ and $96 \%$ ethanol, and stored in $100 \%$ ethanol until use. Alveolar septae were selected and microdissected with a sterile $30 \mathrm{G}$ needle under optical control using the Laser Microbeam System (PALM; Zeiss). Microdissected tissues were then transferred into reaction tubes containing $200 \mu \mathrm{l}$ RNA lysis buffer and samples processed for RNA analysis.

Microarray experiments. Primary ATII cells were isolated from normal and fibrotic mouse lungs 14 days after saline and bleomycin instillation, respectively, and directly used for whole genome microarray analysis. Freshly isolated ATII cells were pooled from 6 different saline- or bleomycin-treated mice. Three independent groups of healthy and fibrotic samples were used for RNA extraction. Total RNA was extracted with RNeasy columns (QIAGEN), according to the manufacturer's instructions, and RNA quality assessed by capillary electrophoresis using the Bioanalyzer 2100 (Agilent Technologies). All samples contained 0.3-1.0 $\mu \mathrm{g}$ RNA, which was preamplified and labeled using the Low Input RNA T7 kit (Agilent Technologies) according to the manufacturer's instructions. Three samples each (saline- and bleomycin-treated mice) were labeled with Cy3 and Cy5. The labeled RNA was hybridized overnight to $44 \mathrm{~K} 60 \mathrm{mer}$ oligonucleotide spotted microarray slides (Human Whole Genome 44K; Agilent Technologies). Slides were washed with different stringencies, dried by gentle centrifugation, and scanned using the GenePix 4100A scanner (Axon Instruments). Data analysis was performed with GenePix Pro 5.0 software, and calculated foreground and background intensities for all spots were saved as GenePix results files. Stored data were evaluated using R software (http://www.cran.r-project.org/) and the limma package from BioConductor (http://www.bioconductor.org). Experimental conditions and results from all microarray experiments are outlined in detail in Supplemental Data, according to the MIAME guidelines.

$R T-P C R$ and $q R T-P C R$. Total RNA was extracted using QIAGEN extraction kits according to the manufacturer's protocol, and cDNAs were generated by reverse transcription using SuperScript II (Invitrogen). Quantitative PCR was performed using fluorogenic SYBR Green and the Sequence Detection System 7700 (Applied Biosystems). Hydroxymethylbilane synthase (HMBS) and hypoxanthine phosphoribosyltransferase 1 (HPRT1) for mouse and human, respectively, and ubiquitously and equally expressed genes that lack pseudogenes, were used as reference genes in all qRT-PCR reactions. PCR was performed using the primers listed in Supplemental Tables 1 and 2, at a final concentration of $200 \mathrm{nM}$. Relative transcript abundance of a gene is expressed in $\Delta \mathrm{Ct}$ values $\left(\Delta \mathrm{Ct}=\mathrm{C}^{\text {reference }}-\mathrm{C}^{\mathrm{target}}\right)$. Relative changes in transcript levels compared with controls are expressed as $\Delta \Delta \mathrm{Ct}$ values $\left(\Delta \Delta \mathrm{Ct}=\Delta \mathrm{Ct}^{\text {treated }}-\Delta \mathrm{Ct}^{\text {control }}\right)$. All $\Delta \Delta \mathrm{Ct}$ values correspond approximately to the binary logarithm of the fold change.

Detection of $\beta$-gal in TOPGAL mice. $\beta$-gal was detected using the X-gal (5-bromo-4-chloro-3-indolyl $\beta$-D-galactosidase) reporter gene staining kit from Sigma-Aldrich. Lung tissues were excised and immediately transferred to fixative containing $0.2 \%$ glutaraldehyde, $5 \mathrm{mM}$ EGTA, $100 \mathrm{mM}$ $\mathrm{MgCl}_{2}$ in $0.1 \mathrm{M} \mathrm{NaPO}_{4}$ (pH 7.3) for 4 hours at $4^{\circ} \mathrm{C}$ with 1 solution change. The samples were transferred to $15 \%$ sucrose in PBS for 4 hours and subsequently to $30 \%$ sucrose in PBS at $4{ }^{\circ} \mathrm{C}$ overnight. Samples were embedded in Tissue-Tek O.C.T., and $15-\mu \mathrm{m}$ sections were cut. The sections were dried at room temperature for 2 hours before staining. For staining, the sections were washed twice with PBS, and the X-gal staining solution was incubated overnight at $37^{\circ} \mathrm{C}$. Counterstaining was performed with hemalaun.

Immunofluorescence and immunohistochemistry. For immunofluorescence analysis, cells were plated on chamber slides, fixed with acetone/methanol
(1:1), and blocked for nonspecific binding sites with $3 \%(\mathrm{~m} / \mathrm{vol})$ BSA. Fixed cells were incubated with the indicated primary antibodies for 60 minutes in PBS containing $0.1 \%(\mathrm{~m} / \mathrm{vol})$ BSA. Indirect immunofluorescence was performed by incubation with FITC- or Alexa 555-conjugated secondary antibodies (Zymed and Molecular Probes [Invitrogen], respectively). Nuclei were visualized by DAPI (Roche Diagnostics). For immunohistochemical analysis, lungs were processed using standard procedures, embedded in paraffin, and mounted on poly-L-lysine-coated slides. Antigen retrieval was performed in $6.5 \mathrm{mM}$ sodium citrate, $\mathrm{pH} 6.0$, in a pressure cooker, after which endogenous peroxidase activity was quenched with $3 \%(v / v) \mathrm{H}_{2} \mathrm{O}_{2}$ for 20 minutes. Proteins of interest were visualized using the HistostainPlus Kit (Zymed; Invitrogen).

Western blot analysis. Cells were harvested, lysed in extraction buffer (20 mM Tris-Cl, 150 mM NaCl, 1 mM EDTA, 1 mM EGTA, 1\% [v/v] Triton $\mathrm{X}-100$, supplemented with Complete Proteinase Inhibitor Cocktail [Merck Biosciences]). Protein extracts were clarified by centrifugation $(6,000 \mathrm{~g})$ at $4^{\circ} \mathrm{C}$. Protein concentrations were determined using the method of Bradford, and $25 \mu \mathrm{g}$ total protein was separated on $10 \%$ SDS-polyacrylamide gels. Separated proteins were transferred onto nitrocellulose membranes (Invitrogen), and the membranes were blocked with 5\% nonfat dry milk in TBS and incubated with the indicated primary antibodies. After washing, membranes were incubated with appropriate secondary, HRP-linked antibodies (Pierce). Proteins were visualized by enhanced chemiluminescence and autoradiography (ECL; Amersham Biosciences, GE Healthcare).

Proliferation assays. Primary ATII cells were plated at a density of $15 \times 10^{4}$ / well in 48-well plates, synchronized for 24 hours in serum-free medium, and treated for 24 hours as indicated. Primary mouse fibroblasts or human lung fibroblasts (HFL1) were seeded at a density of $15 \times 10^{3}$ /well and synchronized for 24 hours in serum-free medium. $\left[{ }^{3} \mathrm{H}\right]$ thymidine $(0.5 \mu \mathrm{Ci} / \mathrm{ml}$; Amersham Biosciences, GE Healthcare) was added to the medium for the last 6 hours of each experiment. Cells were then washed 3 times with PBS and lysed in $10 \%$ trichloroacetic acid, and incorporation of $\left[{ }^{3} \mathrm{H}\right]$ thymidine was determined by liquid scintillation counting. In addition, proliferation was assessed by cell counting 24 hours after stimulation with WISP1, with counting performed at least 3 times for each condition.

Migration assay. Cell migration was determined using a Boyden chamber assay (ThinCert Tissue Culture Inserts, 24 wells, pore size $3.0 \mu \mathrm{m}$; Greiner Bio-One) (67). Cells were cultured for 24 hours to allow their attachment to the membrane and serum starved, and migration was induced by addition of either WISP1 or TGF- $\beta 1$ to the medium in the lower wells, as indicated. After 24 hours, cells were fixed and stained using crystal violet solution (SigmaAldrich), and nonmigrated cells were removed by cotton swabbing.

siRNA transfection. The siRNA duplexes targeting mouse Wisp1 mRNA were obtained from Dharmacon Inc. (Thermo Scientific). Two different siRNA sequences were tested (si\#1 and si\#2). The following sequence (si\#1) was used for all experiments: 5'-UUGAUUGAACUUAUUAGCCTC-3'. The siRNAs $(150 \mathrm{nM})$ were transiently transfected into primary ATII cells using Lipofectamine 2000 Reagent (Invitrogen) at an siRNA/Lipofectamine ratio of $1: 2(\mu \mathrm{g} / \mu \mathrm{l})$. To control for nonspecific gene inhibition of the siRNAs, a negative control siRNA (scrambled) sequence was employed. Cells were harvested and analyzed on mRNA and protein levels 24 hours after the transfection.

Collagen assay. NIH 3 T3 cells or human lung fibroblasts (HFL1) were plated at a density of 30,000 cells/well in 6-well plates, synchronized for 24 hours in serum-free medium, and treated for 24 hours as indicated. Wholelung homogenates were used for in vivo analysis. Total collagen content was determined using the Sircol Collagen Assay kit (Biocolor) (68). Equal amounts of protein lysates were added to $1 \mathrm{ml}$ Sircol dye reagent, followed by 30 minutes of mixing. After centrifugation at $10,000 \mathrm{~g}$ for 10 minutes, the supernatant was aspirated, and $1 \mathrm{ml}$ of alkali reagent was added. Sam- 
ples and collagen standards were then read at $540 \mathrm{~nm}$ in a spectrophotometer (Bio-Rad). Collagen concentrations were calculated using a standard curve with acid-soluble type I collagen.

Compliance measurements. Anesthetized and relaxed mice were tracheotomized, placed in a small animal whole-body plethysmographic chamber (Buxco), and ventilated in volume-driven mode (with a positive end-expiratory pressure [PEEP] of $0 \mathrm{mmHg}$ ). Before measurement of lung compliance, chambers were calibrated with a rapid injection of $300 \mu \mathrm{l}$ room air. Respiration rate was set to $20 / \mathrm{min}$, and ventilation pressure was recorded while inflating the lung at a tidal volume of $200 \mu$ l. Ventilator compliances are given in $\mathrm{kPa} / \mathrm{ml}$ and corrected for mouse whole-body weight.

Statistics. All $\Delta$ Ct values obtained from qRT-PCR and all data derived from compliance measurements were analyzed for normal distribution using the Shapiro-Wilk test, with a $P$ value greater than 0.05 indicating normal distribution. Normality of data was confirmed using quantilequantile plots. All $\Delta \Delta \mathrm{Ct}$ values were analyzed using the 2-tailed, 1-sample $t$ test. Intergroup differences of $\Delta \mathrm{C} t$ values in patients and bleomycin-treated mice were derived using a 1-tailed, 2 -sample $t$ test. Proliferation assay data were analyzed using the Wilcoxon rank-sum test and the signed-rank test. Compliance values were analyzed using the 2 -tailed, 2 -sample $t$ test. All $P$ values obtained from multiple tests were adjusted using the procedure described by Hochberg and Benjamini (69). All results are presented as mean \pm SEM unless otherwise stated and were considered statistically significant when $P$ was less than 0.05 .

1. Martinez, F.J., et al. 2005. The clinical course of patients with idiopathic pulmonary fibrosis. Ann. Intern. Med. 142:963-967.

2. American Thoracic Society and European Respiratory Society. 2002. American Thoracic Society/European Respiratory Society International Multidisciplinary Consensus Classification of the Idiopathic Interstitial Pneumonias. Am. J. Respir. Crit. Care Med. 165:277-304.

3. Selman, M., King, T.E., and Pardo, A. 2001. Idiopathic pulmonary fibrosis: prevailing and evolving hypotheses about its pathogenesis and implications for therapy. Ann. Intern. Med. 134:136-151.

4. Thannickal, V.J., Toews, G.B., White, E.S., Lynch, J.P., 3rd, and Martinez, F.J. 2004. Mechanisms of pulmonary fibrosis. Annu. Rev. Med. 55:395-417.

5. Noble, P.W., and Homer, R.J. 2005. Back to the future: historical perspective on the pathogenesis of idiopathic pulmonary fibrosis. Am. J. Respir. Cell Mol. Biol. 33:113-120.

6. Chapman, H.A. 2004. Disorders of lung matrix remodeling. J. Clin. Invest. 113:148-157.

7. Visscher, D.W., and Myers, J.L. 2006. Histologic spectrum of idiopathic interstitial pneumonias. Proc. Am. Thorac. Soc. 3:322-329.

8. Katzenstein, A.L., and Myers, J.L. 1998. Idiopathic pulmonary fibrosis: clinical relevance of pathologic classification. Am. J. Respir. Crit. Care Med. 157:1301-1315.

9. King, T.E., Jr., et al. 2001. Idiopathic pulmonary fibrosis: relationship between histopathologic features and mortality. Am. J. Respir. Crit. Care Med. 164:1025-1032.

10. Nicholson, A.G., et al. 2002. The relationship between individual histologic features and disease progression in idiopathic pulmonary fibrosis. Am. J. Respir. Crit. Care Med. 166:173-177.

11. Strieter, R.M. 2005. Pathogenesis and natural history of usual interstitial pneumonia: the whole story or the last chapter of a long novel. Chest. 128:526S-532S.

12. Horowitz, J.C., and Thannickal, V.J. 2006. Epithelial-mesenchymal interactions in pulmonary fibrosis. Semin. Respir. Crit. Care Med. 27:600-612.

13. Gharaee-Kermani, M., Ullenbruch, M., and Phan, S.H. 2005. Animal models of pulmonary fibrosis. Methods Mol. Med. 117:251-259.

\section{Acknowledgments}

We are indebted to all members of the Eickelberg laboratory and the Molecular Biology and Medicine of the Lung (MBML) class of 2007 for stimulating discussions. We are particularly grateful to Simone Becker, Anke Wilhelm, Anne Staubitz, and Esther Kuhlmann-Farahat for excellent technical assistance. This study was supported by German Research Foundation (DFG) Excellence Cluster "Cardiopulmonary System" (ECCPS; KliFo 118 to F. Rose, L. Fink, W. Seeger, L. Schaefer, A. Günther, O. Eickelberg); the International Graduate Program "Signaling Mechanisms of Lung Physiology and Disease” (GRK1062 to W. Seeger, L. Fink, A. Günther, O. Eickelberg); an MBML predoctoral fellowship to O.V. Amarie; and the Sofja Kovalevskaja Award by the Alexander von Humboldt Foundation to O. Eickelberg.

Received for publication September 15, 2008, and accepted in revised form January 21, 2009.

Address correspondence to: Oliver Eickelberg, Comprehensive Pneumology Center, Ludwig-Maximilians-University Munich and Helmholtz Zentrum München, Institute of Lung Biology and Disease (iLBD), Ingolstädter Landstrasse 1, 85764 Neuherberg/ Munich, Germany. Phone: 49-89-3187-2319; Fax: 49-89-31872400; E-mail: oliver.eickelberg@helmholtz-muenchen.de.
14. Strieter, R.M., Gomperts, B.N., and Keane, M.P. 2007. The role of CXC chemokines in pulmonary fibrosis. J. Clin. Invest. 117:549-556.

15. Phan, S.H. 2003. Fibroblast phenotypes in pulmonary fibrosis. Am. J. Respir. Cell Mol. Biol. 29:S87-S92.

16. Pardo, A., et al. 2005. Up-regulation and profibrotic role of osteopontin in human idiopathic pulmonary fibrosis. PLoS Med. 2:e251.

17. Selman, M., et al. 2006. Gene expression profiles distinguish idiopathic pulmonary fibrosis from hypersensitivity pneumonitis. Am. J. Respir. Crit. Care Med. 173:188-198.

18. Kim, K.H., et al. 2005. Tissue inhibitor of metalloproteinase-1 deficiency amplifies acute lung injury in bleomycin-exposed mice. Am. J. Respir. Cell Mol. Biol. 33:271-279.

19. Yang, I.V., et al. 2007. Gene expression profiling of familial and sporadic interstitial pneumonia. Am.J. Respir. Crit. Care Med. 175:45-54.

20. Lazar, M.H., et al. 2004. Plasminogen activator inhibitor-1 impairs alveolar epithelial repair by binding to vitronectin. Am. J. Respir. Cell Mol. Biol. 31:672-678.

21. Yeger, H., and Perbal, B. 2007. The CCN family of genes: a perspective on CCN biology and therapeutic potential. J. Cell Commun. Signal. 1:159-164.

22. Brigstock, D.R. 2003. The CCN family: a new stimulus package. J. Endocrinol. 178:169-175.

23. Moon, R.T., Kohn, A.D., De Ferrari, G.V., and Kaykas, A. 2004. WNT and beta-catenin signalling: diseases and therapies. Nat. Rev. Genet. 5:691-701.

24. Logan, C.Y., and Nusse, R. 2004. The Wnt signalling pathway in development and disease. Annu. Rev. Cell. Dev. Biol. 20:781-810.

25. Konigshoff, M., et al. 2008. Functional Wnt signalling is increased in idiopathic pulmonary fibrosis. PLOS ONE. 3:e2142.

26. Chilosi, M., et al. 2003. Aberrant Wnt/beta-catenin pathway activation in idiopathic pulmonary fibrosis. Am. J. Pathol. 162:1495-1502.

27. Chen, C.C., and Lau, L.F. 2008. Functions and mechanisms of action of CCN matricellular proteins. Int. J. Biochem. Cell Biol. Online publication ahead of print. doi:10.1016/j.biocel.2008.07.025.

28. Leask, A., and Abraham, D.J. 2006. All in the CCN family: essential matricellular signalling modulators emerge from the bunker. J. Cell. Sci. 119:4803-4810.

29. Kalluri, R., and Neilson, E.G. 2003. Epithelial-mesenchymal transition and its implications for fibrosis. J. Clin. Invest. 112:1776-1784.

30. Willis, B.C., and Borok, Z. 2007. TGF-beta-induced EMT: mechanisms and implications for fibrotic lung disease. Am. J. Physiol. Lung Cell Mol. Physiol. 293:L525-L534.

31. Kim, K.K., et al. 2006. Alveolar epithelial cell mesenchymal transition develops in vivo during pulmonary fibrosis and is regulated by the extracellular matrix. Proc. Natl. Acad. Sci. U. S. A. 103:13180-13185.

32. Gross, T.J., and Hunninghake, G.W. 2001. Idiopathic pulmonary fibrosis. N. Engl. J. Med. 345:517-525.

33. Gauldie, J., Kolb, M., and Sime, P.J. 2002. A new direction in the pathogenesis of idiopathic pulmonary fibrosis? Respir. Res. 3:1.

34. Lee, C.G., et al. 2004. Early growth response gene 1mediated apoptosis is essential for transforming growth factor beta1-induced pulmonary fibrosis. J. Exp. Med. 200:377-389.

35. Lee, C.G., Kang, H.R., Homer, R.J., Chupp, G., and Elias, J.A. 2006. Transgenic modeling of transforming growth factor-beta(1): role of apoptosis in fibrosis and alveolar remodeling. Proc. Am. Thorac. Soc. 3:418-423.

36. Kuwano, K., et al. 1999. Essential roles of the FasFas ligand pathway in the development of pulmonary fibrosis. J. Clin. Invest. 104:13-19.

37. Kuwano, K., et al. 2002. Mitochondria-mediated apoptosis of lung epithelial cells in idiopathic interstitial pneumonias. Lab. Invest. 82:1695-1706.

38. Uhal, B.D., et al. 1998. Alveolar epithelial cell death adjacent to underlying myofibroblasts in advanced fibrotic human lung. Am. J. Physiol. 275:L1192-L1199.

39. Plataki, M., et al. 2005. Expression of apoptotic and antiapoptotic markers in epithelial cells in idiopathic pulmonary fibrosis. Chest. 127:266-274.

40. Korfei, M., et al. 2008. Epithelial endoplasmic reticulum stress and apoptosis in sporadic idiopathic pulmonary fibrosis. Am. J. Respir. Crit. Care Med. 178:838-846.

41. Thannickal, V.J., and Horowitz, J.C. 2006. Evolving concepts of apoptosis in idiopathic pulmonary fibrosis. Proc. Am. Thorac. Soc. 3:350-356. 
42. Adamson, I.Y., Young, L., and Bowden, D.H. 1988. Relationship of alveolar epithelial injury and repair to the induction of pulmonary fibrosis. Am. J. Pathol. 130:377-383.

43. Fukuda, Y., Ferrans, V.J., Schoenberger, C.I., Rennard, S.I., and Crystal, R.G. 1985. Patterns of pulmonary structural remodeling after experimental paraquat toxicity. The morphogenesis of intraalveolar fibrosis. Am. J. Pathol. 118:452-475.

44. Chilosi, M., et al. 2002. Abnormal re-epithelialization and lung remodeling in idiopathic pulmonary fibrosis: the role of deltaN-p63. Lab. Invest. 82:1335-1345.

45. Haddad, R., and Massaro, D. 1968. Idiopathic diffuse interstitial pulmonary fibrosis (fibrosing alveolitis), atypical epithelial proliferation and lung cancer. Am. J. Med. 45:211-219.

46. Pan, L.H., et al. 2001. Type II alveolar epithelial cells and interstitial fibroblasts express connective tissue growth factor in IPF. Eur. Respir. J. 17:1220-1227.

47. Coalson, J.J. 1982. The ultrastructure of human fibrosing alveolitis. Virchows Arch. A Pathol. Anat. Histol. 395:181-199.

48. Corrin, B., and Dewar, A. 1996. Pathogenesis of idiopathic interstitial pulmonary fibrosis. Ultrastruct. Pathol. 20:369-371.

49. Brody, A.R., and Craighead, J.E. 1976. Interstitial associations of cells lining air spaces in human pulmonary fibrosis. Virchows Arch. A Pathol. Anat. Histol. 372:39-49.

50. Pennica, D., et al. 1998. WISP genes are members of the connective tissue growth factor family that are up-regulated in wnt-1-transformed cells and aberrantly expressed in human colon tumors. Proc. Natl. Acad. Sci. U. S. A. 95:14717-14722.
51. Selman, M., Pardo, A., and Kaminski, N. 2008. Idiopathic pulmonary fibrosis: aberrant recapitulation of developmental programs? PLoS Med. 5:e62.

52. Saxena, N., Banerjee, S., Sengupta, K., Zoubine, M.N., and Banerjee, S.K. 2001. Differential expression of WISP-1 and WISP-2 genes in normal and transformed human breast cell lines. Mol. Cell. Biochem. 228:99-104.

53. Su, F., Overholtzer, M., Besser, D., and Levine, A.J. 2002. WISP-1 attenuates p53-mediated apoptosis in response to DNA damage through activation of the Akt kinase. Genes Dev. 16:46-57.

54. Colston, J.T., et al. 2007. Wnt-induced secreted protein-1 is a prohypertrophic and profibrotic growth factor. Am. J. Physiol. Heart Circ. Physiol. 293:H1839-H1846.

55. Chen, P.P., et al. 2007. Expression of Cyr61, CTGF, and WISP-1 correlates with clinical features of lung cancer. PLOS ONE. 2:e534.

56. Xu, L., Corcoran, R.B., Welsh, J.W., Pennica, D., and Levine, A.J. 2000. WISP-1 is a Wnt-1- and beta-catenin-responsive oncogene. Genes Dev. 14:585-595.

57. Zuo, F., et al. 2002. Gene expression analysis reveals matrilysin as a key regulator of pulmonary fibrosis in mice and humans. Proc. Natl. Acad. Sci. U. S. A. 99:6292-6297.

58. Rosas, I.O., et al. 2008. MMP1 and MMP7 as potential peripheral blood biomarkers in idiopathic pulmonary fibrosis. PLoS Med. 5:e93.

59. Hashimoto, N., Jin, H., Liu, T., Chensue, S.W., and Phan, S.H. 2004. Bone marrow-derived progenitor cells in pulmonary fibrosis. J. Clin. Invest. 113:243-252.

60. Moore, B.B., et al. 2006. The Role of CCL12 in the recruitment of fibrocytes and lung fibrosis. Am. J.
Respir. Cell Mol. Biol. 35:175-181.

61. Phillips, R.J., et al. 2004. Circulating fibrocytes traffic to the lungs in response to CXCL12 and mediate fibrosis. J. Clin. Invest. 114:438-446.

62. Willis, B.C., et al. 2005. Induction of epithelial-mesenchymal transition in alveolar epithelial cells by transforming growth factor-beta1: potential role in idiopathic pulmonary fibrosis. Am. J. Pathol. 166:1321-1332.

63. DasGupta, R., and Fuchs, E. 1999. Multiple roles for activated LEF/TCF transcription complexes during hair follicle development and differentiation. Development. 126:4557-4568.

64. Konigshoff, M., et al. 2007. The angiotensin II receptor 2 is expressed and mediates angiotensin II signalling in lung fibrosis. Am. J. Respir. Cell Mol. Biol. 37:640-650.

65. Eickelberg, O., et al. 2001. Molecular mechanisms of TGF- $\beta$ antagonism by interferon- $\gamma$ and cyclosporine A in lung fibroblasts. FASEB J. 15:797-806.

66. Frank, J., et al. 2003. Transforming growth factorbeta1 decreases expression of the epithelial sodium channel alphaENaC and alveolar epithelial vectorial sodium and fluid transport via an ERK1/2-dependent mechanism. J. Biol. Chem. 278:43939-43950.

67. Yu, H., et al. 2008. Transgelin is a direct target of TGF-\{beta\}/Smad3-dependent epithelial cell migration in lung fibrosis. FASEB J. 22:1778-1789.

68. Kitowska, K., et al. 2008. Functional role and species-specific contribution of arginases in pulmonary fibrosis. Am. J. Physiol. Lung Cell Mol. Physiol. 294:L34-L45.

69. Hochberg, Y., and Benjamini, Y. 1990. More powerful procedures for multiple significance testing. Stat. Med. 9:811-818. 